Article

\title{
Moving towards Sustainability: Road Grades and On-Road Emissions of Heavy-Duty Vehicles-A Case Study
}

\section{Wendan Zhang ${ }^{1,2}$, Jian $\mathrm{Lu}^{3}$, Ping Xu ${ }^{1,2}$ and Yi Zhang ${ }^{1,2, *}$}

1 State Key Laboratory of Ocean Engineering, Shanghai Jiao Tong University, Shanghai 200240, China; E-Mails: fruits@sjtu.edu.cn (W.Z.); shanon@sjtu.edu.cn (P.X.)

2 Transportation Research Center, Shanghai Jiao Tong University, Shanghai 200240, China

3 Key Laboratory of Road and Traffic Engineering of Ministry of Education, Tongji University, Shanghai 200092, China; E-Mail: jianjohnlu@sjtu.edu.cn

* Author to whom correspondence should be addressed; E-Mail: darrenzhy@sjtu.edu.cn; Tel./Fax: +86-21-3420-7275.

Academic Editor: Tan Yigitcanlar

Received: 13 June 2015 / Accepted: 7 September 2015 / Published: 15 September 2015

\begin{abstract}
On-road vehicle emissions are one of the major sources of transport emissions. As a key design factor, road grades (or road slopes) have significant effects on on-road vehicle emissions, particularly on Heavy-Duty Vehicles (HDVs). However, the research into the relationship between road grades and on-road vehicle emissions is very rare in China. Taking a road network in Taiyuan, China, as a study area, this paper explored the influences of road grades on carbon monoxide (CO), hydrocarbon $(\mathrm{HC})$, and nitrogen oxide $\left(\mathrm{NO}_{\mathrm{x}}\right)$ emissions of HDVs. Combining emissions data collected by Portable Emission Measurement System (PEMS) with Vehicle Specific Power (VSP), we developed an emission rate model of HDVs. Then, we integrated it with the traffic simulation model VISSIM to attain the emissions of HDVs on nine scenarios differentiated by road grades. The results showed that the three emissions are found to be highly correlated to road grades, among which the $\mathrm{CO}$ emissions are most sensitive to the change of road grades and the $\mathrm{HC}$ emissions least. Compared to the emissions at $0 \%$ grade, the emissions at $4 \%$ grade will be boosted from $39.0 \%$ to $60.6 \%$. The $\mathrm{CO}$ and $\mathrm{NO}_{\mathrm{x}}$ emissions increase with the road grades in all nine scenarios, while the variations of $\mathrm{HC}$ emissions in different scenarios were complicated. The findings of this research will provide insights for policy-makers, scholars, and practitioners into strategies for improving road design to reduce traffic emissions and develop sustainable transportation in China.
\end{abstract}


Keywords: road grades; heavy-duty vehicles; emissions; sustainable transportation; China

\section{Introduction}

The combustion of fossil fuels by vehicles leads to road traffic emissions, which are one of the most significant sources of primary air pollutants. Air pollution is a major risk to health and to the environment, in developed and developing countries alike. Most sources of outdoor air pollution are well beyond the control of individuals and demand action by cities, as well as national and international policymakers in sectors like transport and energy waste management [1]. Road transport often appears as the single most important source of urban pollutant emissions in source apportionment studies, and road transport is likely to remain a large contributor to air pollution in the coming decades [2-4].

Motor vehicle emissions are a primary concern because of their potential detriment to local air quality and global atmospheric conditions. Although significant progress has been made to limit the pollutant emissions from individual vehicles, emissions from conventional gasoline-powered motor vehicles remain a concern in the United States (U.S.) and account for the majority of petroleum consumption [5]. In Europe, with the successful implementation of catalytic converters in gasoline vehicles, the transport sector, which used to be the highest emitter of Carbon Monoxide (CO), has reduced its CO emissions significantly (61\% from 2003 to 2012). The transport sector is also the largest contributor to Nitrogen Oxides $\left(\mathrm{NO}_{\mathrm{x}}\right)$ emissions, accounting for $46 \%$ of total European Union (EU)-28 emissions in 2012 [6]. The precise information of on-road vehicle emissions is crucial for the evaluation of the contribution of road traffic in general. For this reason, major efforts are being made for the reduction of polluting emissions from road transport all over the world [7].

Humanity has entered a new era of sustainability challenges, in striving to prevent our society and future generations from tipping into disastrous states, sustainable development has remained one of the primary policy goals in the large majority of countries around the world. Even the transport infrastructure sector has come to realize that development must not come at the expense of environmental and social objectives [8-10]. Over the past several decades, with rapid urbanization, many cities across the world, especially in developed countries, have experienced explosive trends in road construction and motorization. Although this has greatly increased people's mobility in daily life, it has also led to a series of problems, such as exhausting the finite fuel reserves and raising vehicle emissions. Therefore, the sustainability of cities is threatened by excessive automobile dependency [11].

How do road design and traffic management factors (e.g., road grades, lane width, and speed limit) influence on-road vehicle emissions? Currently, studies focusing on the relationships between significant factors and on-road vehicle emissions remain generally weak, providing insufficient support for strategies and guidelines from the perspective of improving road design and management. Therefore, it is imperative for policy-makers, scholars, and practitioners to investigate the factors significantly associated with on-road vehicle emissions to draw up strategies and guidelines to achieve the goal of reducing vehicle emissions and developing sustainable transportation. With data collected in Taiyuan, China, the aim of this paper is to explore the relationship between road grades and $\mathrm{CO}$, Hydrocarbons (HC) and NOx emissions of Heavy-Duty Vehicles (HDVs) in, and provide guidance for 
the design of road grades that facilitates the reduction of on-road vehicle emissions and the development of sustainable transportation.

\section{Literature Review}

\subsection{Road Grades and On-Road Vehicle Emissions}

Over the past several decades, the volume of literature on the relationship between various factors and on-road vehicle emissions in the Western context has exploded, explaining why and how those factors might influence on-road vehicle emissions from diversified perspectives [12-20]. Among those studies, an increasing number of studies have explored the influences of road design factors, e.g., template (width, full bench/side cast), curve widening, and grade (or slope), with an attempt to reduce emissions through the improvement of road design methodology [15,17]. In Table 1, we listed some studies on the changes of fuel consumption and emissions (Carbon Dioxide $\left(\mathrm{CO}_{2}\right), \mathrm{CO}, \mathrm{HC}$, and $\mathrm{NO}_{\mathrm{x}}$ ) with the change of road grades. The information in Table 1 indicated that:

(a) Three out of six papers considered uphill only and the other three analyzed both uphill and downhill.

(b) Generally, positive road grade yields higher emissions and negative road grade results in lower emissions.

(c) Among the three papers analyzing both uphill and downhill, Boriboonsomsin and Barth [15], and Frey et al. [21] concluded that the fuel change at locations with negative grade is higher than the fuel change at locations with positive grade. However, Boroujeni and Frey had the opposite conclusion [22].

It must be noted that these literatures deduced their conclusions under the condition of many restrictions, such as the test sites, categories of vehicles and fuels, driving behaviors, etc. Taking vehicles as an example, the first and third papers in Table 1 used light-duty vehicle while the sixth used passenger cars and trucks. Therefore, each paper in Table 1 has its own limited conditions, and they may not represent the situation at other conditions. In addition to studies in Table 1, some other papers also discussed the relationship of road grades on engine performance or vehicle emissions. Wyatt et al. found it was not correct to assume that the increased emissions on uphill slopes will be offset by the decreased emissions on paired downhill sections [23]. On the contrary, Prati et al., indicated that the presence of both positive and negative grades along the same route has the effect of balancing these opposite influences on engine performance [24]. Alam et al., observed that at lower grades, the change rates of emissions were higher and as the grade increases the change rates decrease [25]. Considering the brakes, Kern et al., through the use of a model, found that vehicle emissions rose sharply once hills were sufficiently steep to warrant the use of brakes [26]. In the study of Silva et al., the average $\mathrm{HC}$ and $\mathrm{CO}$ emissions for the entire segments slightly decreases for scenarios involving grades between $1 \%$ and $3 \%$ and then increase relatively to the baseline [13]. 
Table 1. Studies on the changes of fuel consumption and emissions with the change of road grades.

\begin{tabular}{|c|c|c|c|c|c|c|c|c|}
\hline \multirow{2}{*}{ NO. } & \multirow{2}{*}{ References } & \multirow{2}{*}{ Grade Range (\%) } & \multicolumn{4}{|c|}{ Change Rate of Emission (\%) } & \multirow{2}{*}{$\begin{array}{c}\text { Change Rate of Fuel } \\
\text { Consumption }(\%)\end{array}$} & \multirow{2}{*}{$\begin{array}{l}\text { Mile-Per-Gallon } \\
\text { Fuel Economy }\end{array}$} \\
\hline & & & CO & $\mathrm{HC}$ & NO $_{x}$ & $\mathrm{CO}_{2}$ & & \\
\hline 1 & Silva et al. [13] & from $0 \%$ to $+8 \%$ & $4-73$ & $3-47$ & $24-380$ & $2-64$ & & \\
\hline 2 & Zhang and Frey [27] & $\geq 5 \%$ & $60-140$ & $60-110$ & $180-450$ & $40-90$ & & \\
\hline \multirow{3}{*}{3} & \multirow{3}{*}{$\begin{array}{l}\text { Boroujeni and } \\
\text { Frey [22] }\end{array}$} & negative actual grade $(1102 *)$ & 1 & -1 & -7 & & -12 & \\
\hline & & positive actual grade $\left(1111^{*}\right)$ & 38 & 22 & 42 & & 14 & \\
\hline & & all segments $(2213 *)$ & 10 & 4 & 10 & & 1 & \\
\hline \multirow{3}{*}{4} & \multirow{3}{*}{$\begin{array}{l}\text { Boriboonsomsin } \\
\text { and Barth [15] }\end{array}$} & $6 \%$ followed by $-6 \%$ & & & & & $15-20$ & \\
\hline & & positive & & & & & & $\begin{array}{l}\text { from }-2 \text { to } \\
-1.5 \text { times }\end{array}$ \\
\hline & & negative & & & & & & 2 times \\
\hline \multirow{4}{*}{5} & \multirow{4}{*}{ Frey et al. [21] } & positive & & & & & $16-22$ & \\
\hline & & negative & & & & & from -22 to -24 & \\
\hline & & total & & & & & from -5 to 0 & \\
\hline & & from $0 \%$ to $+5 \%$ & & & & & $40-100$ & \\
\hline \multirow{3}{*}{6} & \multirow{3}{*}{$\begin{array}{l}\text { Cicero-Fernândez } \\
\text { et al. } \text { [17] }\end{array}$} & from $0 \%$ to $+7 \%$ & $3.0 \mathrm{~g} / \mathrm{mile} /+1 \%$ grade & $0.04 \mathrm{~g} / \mathrm{mile} /+1 \%$ grade & & & & \\
\hline & & $\begin{array}{l}4.5 \% \text { (vehicle with four } \\
\text { passengers) }\end{array}$ & $10.2 \mathrm{~g} / \mathrm{mile}$ & $0.07 \mathrm{~g} / \mathrm{mile}$ & & & & \\
\hline & & $\begin{array}{c}4.5 \% \text { and } 6.7 \% \mathrm{CO} \\
\text { (air conditioning) }\end{array}$ & $31.9 \mathrm{~g} / \mathrm{mile}$ & $0.07 \mathrm{~g} / \mathrm{mile}$ & & & & \\
\hline
\end{tabular}

* denotes the number of the segments with slope. 


\subsection{Review of Previously Research Methods}

The most-frequently used method of "road design-on-road vehicle emissions" related studies is constituted by the collection of emissions data, development of an emission rate model, integration of emission rate model and traffic simulation models, and statistical analysis [12,14].

\subsubsection{Collection of Emissions Data}

On-board Portable Emission Measurement System (PEMS) is widely used in on-road vehicle emissions studies [13]. PEMS is able to collect the data of second-by-second emissions and speed variation of the vehicle under real-world conditions at any location traveled by the vehicle [17]. The relationship between second-by-second speed variation and on-road vehicle emissions can be used to build emission rate model. It is certain that this kind of emission rate model is more reliable than other microscopic emission models, because measurements are obtained during real-world driving, eliminating the concern about non-representativeness that is often an issue with dynamometer testing, and at any location, eliminating the site restrictions inherent in remote sensing [28].

\subsubsection{Development of Emission Rate Model}

Since the 1970s, different emission rate model were developed to estimate transport emissions with the purpose of focusing control strategies and transportation planning on those that are most effective, predicting how different strategies will effect local emissions, and measuring progress in reducing emissions over time. The Mobile Source Emissions Factor (MOBILE) model, first developed in the late 1970s in the U.S., is an emission rate model for predicting gram per mile emissions of $\mathrm{CO}_{2}, \mathrm{CO}$, $\mathrm{HC}$, and $\mathrm{NO}_{\mathrm{x}}$, particulate matter (PM), and toxics from cars, trucks, and motorcycles under various conditions [29]. MOBILE has been replaced by Motor Vehicle Emission Simulator (MOVES) as U.S. Environmental Protection Agency's (EPA) official model for estimating emissions from cars, trucks and motorcycles. MOVES is able to estimate emissions for mobile sources covering a broad range of pollutants and allows multiple scale analysis [30]. Another emission rate model, Comprehensive Modal Emissions Model (CMEM), was initially developed in the late 1990s with sponsorship from the National Cooperative Highway Research Program (NCHRP) and EPA to fulfill the need for microscopic emissions modeling. CMEM is microscopic in the sense that it predicts second-by-second tailpipe emissions and fuel consumption based on different modal operations from the in-use vehicle fleet [31]. Outside the U.S., Davis et al., developed the International Vehicle Emissions (IVE) model to make estimates of local air pollutants (criteria pollutants), greenhouse gas emissions, and toxic pollutants from motor vehicles [32].

Previous studies found out that the instantaneous vehicle emissions were highly correlated to the power output, i.e., Vehicle Specific Power (VSP, kw/ton) [33]. It can be defined as the engine power output per unit vehicle total mass and takes into account aerodynamic drag, tire rolling resistance and road grade. VSP is a variable that relates the second-by-second vehicle emissions with the vehicle's instantaneous driving modes, which can be calculated from the instantaneous speed, acceleration and road grade [18]. Recently, VSP has been well accepted and widely applied in studies on emission modeling and prediction [34]. In China, the VSP-based emission rate model has been studied in the 
past several years. Qi et al. developed microscopic emissions models that predict vehicle fuel consumption and emissions by using instantaneous speed and acceleration and deceleration as explanatory variables [35].

\subsubsection{Integration of Emission Rate Model and Traffic Simulation Models}

PTV VISSIM is a microscopic multi-modal traffic flow simulation software package developed by PTV Planung Transport Verkehr AG in Karlsruhe, Germany. The name is derived from "Verkehr In Städten-SIMulationsmodell" (German for "Traffic in cities-simulation model"). VISSIM was first developed in 1992 and the latest version is PTV VISSIM 7 which was released in 2014. Song et al., studied the applicability of traffic simulation model VISSIM in vehicle emission estimations based on VSP distribution [36]. Bing et al., and Zhang et al., investigated the relationship of intersection lane configuration and speed limit to vehicle emissions with VSP-based emission rate model [12,14].

Microscopic traffic simulation models, e.g., VISSIM, Paramics, were employed together with emission rate model for more complicated analysis. With the integration of VISSIM and CMEM, Noland et al., evaluated the impact of the changes of road capacity on vehicle emissions [19]. Stevanovic et al. linked VISSIM and CMEM to optimize signal timings and minimize fuel consumption and $\mathrm{CO}_{2}$ emissions [20]. By integrating VISSIM with MOVES, Lv et al. investigated the effects of traffic signal coordination on emissions and compared it with their effects on operational performance measures of delay and stops [37]. Paramics, another commonly used microscopic traffic simulation model, has also been employed in analyzing on-road vehicle emissions. Using Paramics, Chamberlin et al., compared the emissions estimates from MOVES to those generated by CMEM [16]. Bartin et al. integrated MOBILE6.2 in Paramics and presented a microscopic simulation-based estimation of the spatiotemporal change in air pollution levels as a result of Electronic Toll Collection (ETC) deployment on a large-scale traffic network [38]. By integrating Paramics with CMEM, Boriboonsomsin et al., estimated and compared vehicle emissions contributed from two types of High Occupancy Vehicle (HOV) lane configurations [15].

\subsection{Studies on On-Road Emissions of HDVs in China}

Although some scholars have preliminary established VSP based emission rate model with data collected in China, they rarely focused on on-road emissions of HDVs. HDVs, as diesel vehicles, are responsible for nearly 20 percent of $\mathrm{CO}_{2}$ emissions from transportation in China, and at the same time, produce high levels of $\mathrm{CO}, \mathrm{HC}, \mathrm{NO}_{\mathrm{x}}$, and $\mathrm{PM}$. These emissions are not only related to global warming and environmental disruption, but are also associated with bronchitis, asthma, and other lung diseases, and are responsible for millions of premature deaths worldwide [39]. Meanwhile, as a key geometric design factor, road grades are found to have significant effects on on-road vehicle emissions, particularly on HDVs [15,40,41]. However, research into the relationship between road grades and emissions of HDVs is very rare, especially in China.

In this paper, we present research results from a case study aiming at unraveling the influences of road grades on $\mathrm{CO}, \mathrm{HC}$ and $\mathrm{NO}_{\mathrm{x}}$ emissions of HDVs, with data collected from Taiyuan Metropolitan Area, China. The reason we focus on $\mathrm{CO}, \mathrm{HC}$ and $\mathrm{NO}_{\mathrm{x}}$ emission is because they account for nearly $90 \%$ of total on-road vehicle emissions in China [42]. In accordance with national standard, the HDVs 
in this study are diesel vehicles with a weight of over $3500 \mathrm{~kg}$. Firstly, we establish an emission rate model of HDVs under VSP-bins with the data collected from a PEMS, OBEAS-3000 (developed by Xiamen Tongchuang Detection Technology Co., Ltd, Xiamen, China), in Taiyuan. Secondly, with the integration of emission rate model of HDVs and VISSIM, we calculate the $\mathrm{CO}, \mathrm{HC}$, and $\mathrm{NO}_{\mathrm{x}}$ emissions of HDVs in 9 scenarios differentiated from road grades (from $0 \%$ to $4 \%$ ). Then, we statistically analyze how road grades are associated with the $\mathrm{CO}, \mathrm{HC}$, and $\mathrm{NO}_{\mathrm{x}}$ emissions and the total equivalent emissions of HDVs. Finally, based on the research findings, we discuss strategies oriented towards reducing emissions of HDVs. The findings of this study will provide insights for policy-makers, scholars, and practitioners into the improvement of road grade design with an attempt to reduce traffic emissions and develop sustainable transportation in China.

\section{Data and Method}

\subsection{Study Area}

Since the implementation of reform and opening up policy in 1978, China has experienced a major demographic transition of rapid and intense urbanization and motorization [43-45]. From 1978-2014, the level of urbanization in China tripled from $17.9 \%-54.77 \%$, and the level of motorization boomed at $20 \%$ annually $[46,47]$. This situation has contributed to China's increasingly severe transport and environmental problems [48]. Among those problems, transport energy consumption and emissions have become issues of public concern. By the end of 2014, in China's total emissions, the transport emissions have covered over $25 \%$ [49], among which on-road vehicle emissions covered over $85 \%$ of all transport emissions [8]. In the Copenhagen Accord of the 2009 United Nations Climate Change Conference, the Chinese government has committed to reducing the emissions per unit Gross Domestic Product (GDP) by $40 \%-45 \%$ by 2020 as compared to 2005 [50]. In response to that goal, the Ministry of transport of the People's Republic of China has also committed to reduce on-road vehicle emissions by $11 \%$ in 2015 as compared to in 2005 .

We chose a road network in Taiyuan Metropolitan Area, China, as the study area. Taiyuan is the capital and largest city of North China's Shanxi province, with a total population of 429.89 million inhabitants on $6959 \mathrm{~km}^{2}$ (by the end of 2014) [51]. Mountainous regions and hills make up 80.1\% of the whole Shanxi province, leading to bigger road grades than plain areas [51]. Shanxi Province is a leading producer of coal in China, with more coal companies than any other province and an annual production exceeding 300 million metric tons [51]. HDVs are major players in Shanxi's transport sector for coal transportation. However, they also produce vast emissions, raising increasing concerns about environmental disruption and public health. Therefore, examining the influences of road grades on HDVs in Shanxi would facilitate emissions reduction through the improvement in road design.

The road network we chose in Taiyuan included five roads, Wucheng Road (1.4 km), Renmin Road $(1.4 \mathrm{~km})$, Kangning Street (1.5 km), Changsheng Street $(1.3 \mathrm{~km})$, and Tongda Street (1.3 km) (Figure 1). This road network is located at south Taiyuan, a newly urbanized area where there used to be villages and farmlands. The road network was chosen because of its representativeness in Shanxi Province, featuring high ratios of HDVs and big road grades. The HDV ratios of traffic volume on the five roads, especially on Wucheng Road and Renmin Road, are as high as $20 \%$. That is partly due to the fact they 
are major arterials connecting the urban core of Taiyuan to the suburban and rural areas. The road grades of the chosen network range from $0 \%-4 \%$, which is in accordance with the range of lowest and highest grades of ascent road segments regulated in the national road design manual.

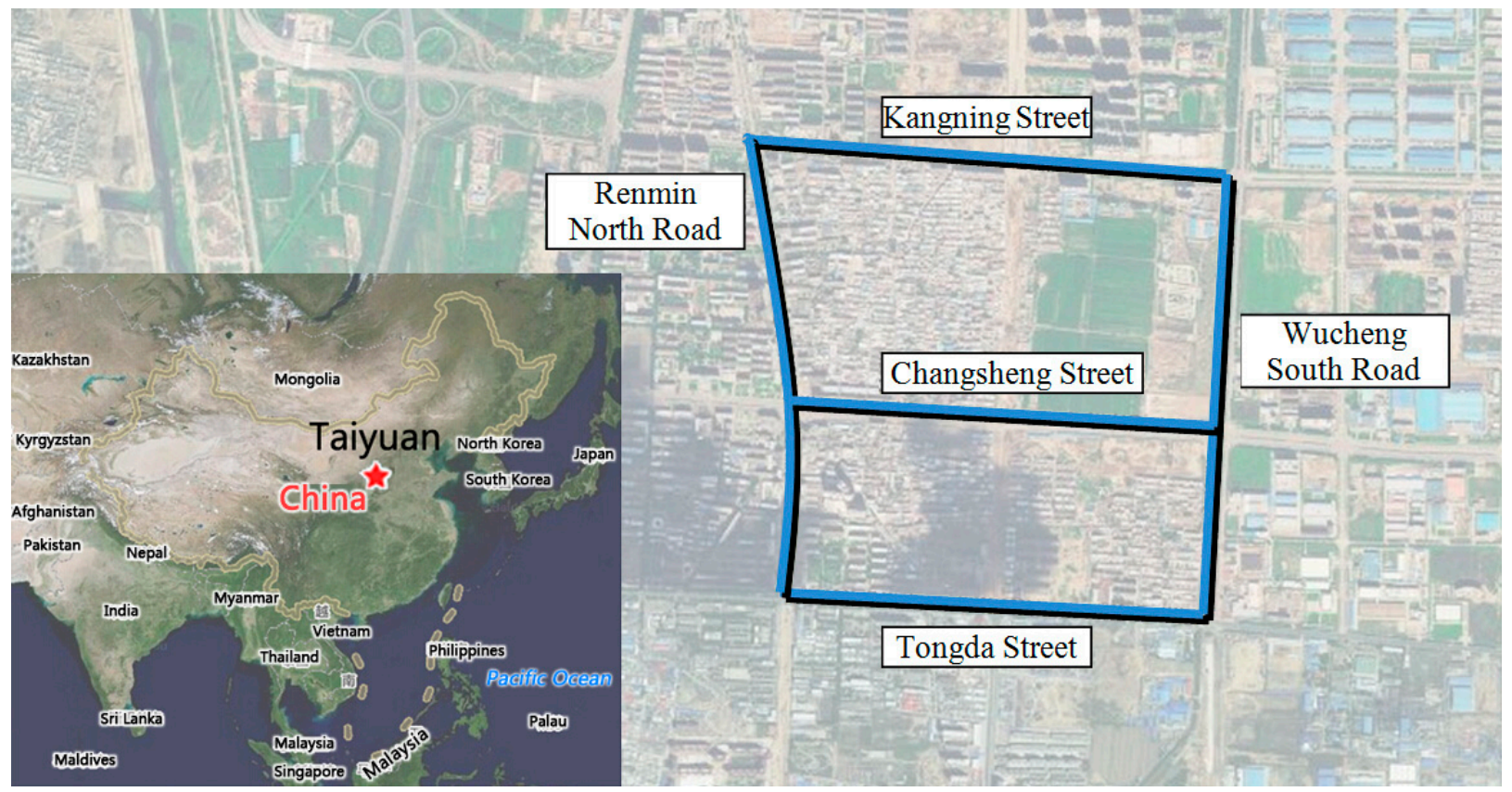

Figure 1. Study area (Courtesy of Baidu).

\subsection{Development of Emission Rate Model Based on On-Board PEMS and VSP}

\subsubsection{Data Collection}

In this study, we collected three types of data: traffic volume of HDVs and light-duty vehicles, road grades design, and on-road HDV emissions. The traffic volume data were counted on the morning and afternoon peak hours during 7:30-9:30 a.m. and 4:30-6:30 p.m. on 12 November 2013. The data of road grades design were collected from Transport Department of Shanxi Province. The on-road vehicle emissions data were collected by an on-board PEMS, OBEAS-3000, on the same day of traffic volume count.

On-board PEMS is able to collect second-by-second speed and emissions variation of the vehicle under real-world conditions. OBEAS-3000 is an integrated and high precision PEMS developed by the Xiamen Tong Chuang Detection Technology Co, Ltd. and can be used in petrol and diesel engines in light and heavy-duty vehicles [12]. OBEAS-3000 is comprised of five-gas analyzer, engine diagnostic scanner, on-board computer and Global Positioning System (GPS) (Figure 2). The five-gas analyzer E-BOX PC is imported with original packaging from SIEMENS, Germany, which is used to measure the volume percentage of $\mathrm{CO}, \mathrm{CO}_{2}, \mathrm{HC}, \mathrm{NO}_{x}$, and $\mathrm{O}_{2}$ in the vehicle exhaust. Simultaneously, the engine scanner is connected to the On-Board Diagnostics (OBD) link of the vehicle, where engine and vehicle data are downloaded during vehicle operation. Engine data is used to calculate the volume flow rate of $\mathrm{CO}, \mathrm{CO}_{2}, \mathrm{HC}, \mathrm{NO}_{x}$, and $\mathrm{O}_{2}$ in the vehicle exhaust, which is combined with the volume percentage to output the instantaneous mass flow rate $(\mathrm{mg} / \mathrm{s})$. The laptop is used to record the different parameters, such as temperature, humidity, and information regarding each test vehicle. The GPS is used to improve 
the precision of speed and acceleration. In addition, events during trips are also recorded with the GPS and laptop computer, including the time at which the vehicle crosses the centerline of key intersections and the path the vehicle travels.

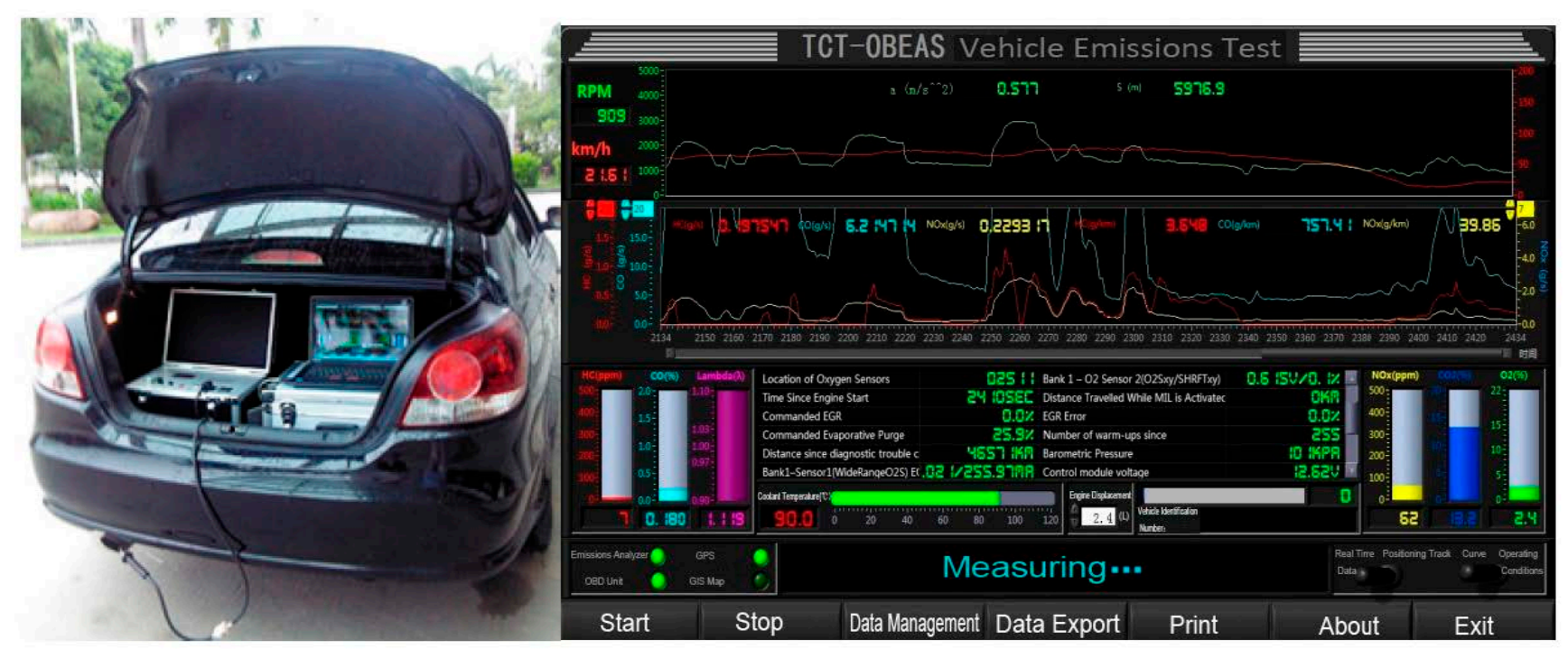

Figure 2. The application and user interface of OBEAS-3000.

According to the vehicle type and vehicle weight data from Transport Department of Shanxi Province, the HDVs weighing over 10 ton occupied nearly $70 \%$ of the HDV fleet in the chosen road network. Therefore, one heavy-duty vehicle produced by Chinese manufacturer First Automotive Works (FAW) (Table 2) was selected to collect on-road emissions data by OBEAS-3000. The data included second-by-second $\mathrm{CO}, \mathrm{HC}$ and $\mathrm{NO}_{\mathrm{x}}$ emissions, and the speed and acceleration. The durations of each test were about $30 \mathrm{~min}$ and 10 tests were conducted. The average test distance is about $15 \mathrm{~km}$. More than 16,000 groups of valid records were collected from the vehicles.

Table 2. Basic information of the testing vehicles.

\begin{tabular}{cc}
\hline Parameters & HDV \\
\hline Manufacturer & FAW * Car Co., Ltd \\
Brand & Jie Fang \\
Year of Manufacture & 2012 \\
Total Mass (kg) & 15790 \\
Engine Displacement (L) & 6.6 \\
Fuel Type & diesel \\
Emission Standard & Euro IV with EGR * FEUP * \\
Mileage & 10000 \\
\hline
\end{tabular}

* FAW stands for First Automotive Works, EGR stands for Exhaust Gas Recirculation, and FEUP stands for FAW Electronic Unit Pump. 


\subsubsection{Definition of VSP \& VSP-Bin}

Recent studies have shown that the instantaneous vehicle emissions were highly correlated to VSP [34]. Therefore, the variable based on VSP, rather than instantaneous speed or average speed, is the core explanatory variable for analyzing energy consumption and emission of vehicles. In this study, we employed VSP to develop an emission rate model. VSP is a widely accepted explanatory variable, generally defined as the power required per unit mass of the vehicle, also known as the ratio of the power of the vehicle. According to existing literature, the formula of VSP for HDVs in China is expressed as follows [52]:

$$
V S P_{H D V}=v \times(a+9.807 \times \sin \theta+0.186333)+\frac{3.702456}{m}
$$

where $v$ is the vehicle speed $(\mathrm{m} / \mathrm{s}) ; a$ is the acceleration $\left(\mathrm{m} / \mathrm{s}^{2}\right) ; \theta$ is the angle of road grade; $m$ is the vehicle weight (ton).

In order to better capture the emission characteristics under the concept of VSP, VSP values were usually distributed into bins, and the vehicle emissions are averaged under the same VSP-bin [53].

\subsubsection{Emission Rate Model Based on On-Board PEMS and VSP}

With collected data, we were able to calculate the VSP values and group the second-by-second emissions data into different VSP-bins. The principle of VSP-bin division is to keep the balance of each bin in emission rates and emission contributions [12]. After an analysis of emission data, it was found that $97.6 \%$ of all data fell into the VSP range of -25 to $25(\mathrm{kw} / \mathrm{t})$. Furthermore, we made sure that the numbers of emission data under each VSP-bin were no less than 20. The specific frequency distribution of VSP and proportion of different VSP range are illustrated in Figure 3 and Table 3. In Table 4, we listed the resulting emission rates of HDVs under each VSP-bin.

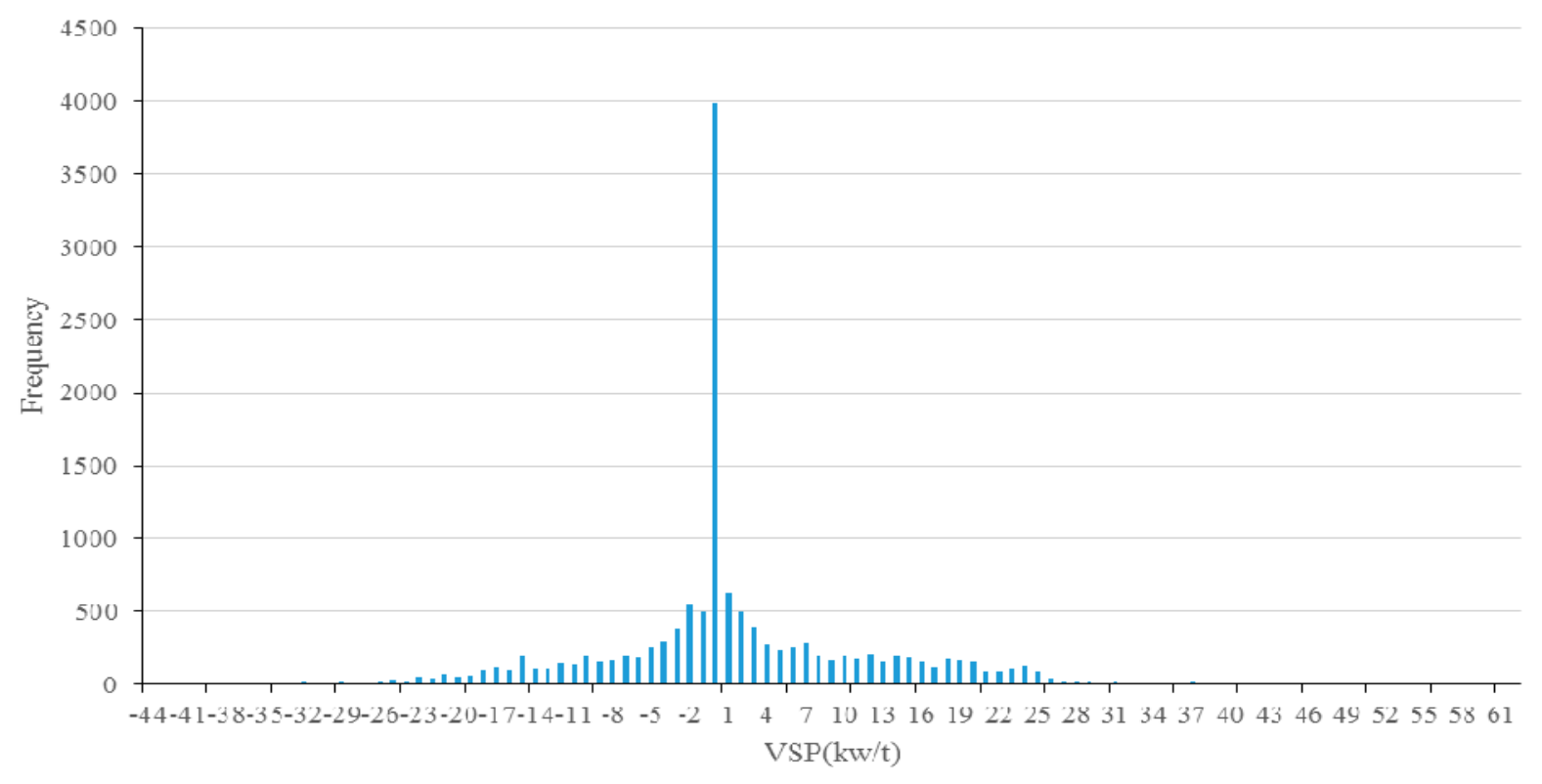

Figure 3. Frequency distribution of VSP. 
Table 3. Proportion of different VSP range.

\begin{tabular}{cc}
\hline VSP Range & Proportion (\%) \\
\hline$[-5,5]$ & 57.80 \\
{$[-10,10]$} & 72.08 \\
{$[-15,15]$} & 83.74 \\
{$[-20,20]$} & 92.26 \\
{$[-25,25]$} & 97.59 \\
{$[-30,30]$} & 98.65 \\
{$[-35,35]$} & 99.24 \\
{$[-40,40]$} & 99.57 \\
\hline
\end{tabular}

Table 4. Emission rates of HDV under VSP-bin (based on experimental values measured on one vehicle).

\begin{tabular}{cccccc}
\hline VSP-bins & Range & $\mathbf{C O}(\mathbf{m g} / \mathbf{s})$ & $\mathbf{H C}(\mathbf{m g} / \mathbf{s})$ & $\mathbf{N O}_{\mathbf{x}}(\mathbf{m g} / \mathbf{s})$ & Frequency \\
\hline 1 & $(-\infty,-25)$ & 1.3250 & 1.7616 & 7.1723 & 100 \\
2 & {$[-25,-20]$} & 0.9457 & 2.6399 & 7.6521 & 230 \\
3 & {$[-20,-14]$} & 1.4794 & 3.2946 & 8.7245 & 617 \\
4 & {$[-14,-10]$} & 1.3027 & 3.3108 & 12.0206 & 498 \\
5 & {$[-10,-5]$} & 3.6174 & 4.7910 & 6.4120 & 888 \\
6 & {$[-5,-2]$} & 5.1957 & 6.9809 & 11.4792 & 935 \\
7 & {$[-2,-1]$} & 11.4613 & 2.2593 & 33.8444 & 553 \\
8 & {$[-1,0]$} & 7.9797 & 1.0422 & 21.4202 & 498 \\
9 & {$[0,1]$} & 9.9653 & 0.9430 & 36.9548 & 3993 \\
10 & {$[1,2]$} & 15.1145 & 3.0147 & 60.0636 & 631 \\
11 & {$[2,5]$} & 23.8573 & 2.9065 & 62.1429 & 1168 \\
12 & {$[5,10]$} & 37.2366 & 4.6050 & 93.3285 & 1144 \\
13 & {$[10,14]$} & 41.1333 & 3.1037 & 66.9862 & 738 \\
14 & {$[14,20]$} & 24.9549 & 3.5288 & 81.3605 & 989 \\
15 & {$[20,25]$} & 12.5323 & 2.7615 & 94.7466 & 574 \\
16 & {$[25,+\infty)$} & 16.6543 & 3.1497 & 106.1606 & 322 \\
\hline
\end{tabular}

\subsection{Integration of Emission Rate Model and VISSIM}

The simulation model used in this study is VISSIM (version 4.3) as developed by PTV Planung Transport Verkehr AG in Karlsruhe, Germany. VISSIM is a stochastic, microscopic, time-step and behavior-based simulation model [54], integrating a psychophysical driver behavior model developed by Weidmann and a traffic model that is discrete and stochastic using driver-vehicle-units as single entities [55]. The parameters such as instantaneous speed, acceleration and vehicle weight, which are input for VSP calculation, could be generated from VISSIM.

\subsubsection{Calibration and Validation of Microscopic Traffic Simulation Model, VISSIM}

Microscopic traffic simulation models have been widely used because simulation is user-friendly, safer, faster, and less expensive than field implementation and testing. In practice, simulation model based analyses have often been conducted under default parameter values or best guessed values. 
At times, simulation model outputs could result in unrealistic estimates if the simulation model is not properly calibrated and validated. Thus, calibration and validation of simulation models are crucial steps in assessing their value in transportation operations, planning, and policy [56].

Microscopic simulation models contain a lot of independent parameters with default values for each variable. However, the users can input a range of values for the parameters. Model calibration is defined as the process by which the individual components of the simulation model are adjusted or tuned so the model can accurately represent field measured or observed traffic conditions, and model validation tests the accuracy of the model by comparing traffic flow data generated by the model with that collected from the field [57].

In this paper, we referred to the calibration and validation procedure developed by Park et al. [1] and Sun et al. [58,59] whose case study is VISSIM and the test-bed network is a little similar to our research. Specifically, the procedure has 10 steps: (a) measure of effectiveness selection (include target value and calibration target); (b) data collection; (c) calibration parameter identification; (d) initial evaluation; (e) experimental design; (f) run simulation; (g) surface function development; (h) candidate parameter set generations; (i) evaluation and (j) validation through new data collection.

The implementation of the procedure includes:

(a) Two measures of performance were selected for the calibration and validation procedure, which were (1) eastbound left-lane travel times on Tongda Road; and (2) the maximum queue length between the intersections of Renmin Road and Changsheng Road. These performance measures were chosen because of their ease of collection from the field and from VISSIM output files. The target value of average field eastbound left-lane travel time was $155.74 \mathrm{~s}$, and the field maximum queue length was $43.2 \mathrm{~m}$. The calibration target is the field data is in the $95 \%$ confidence interval of the simulation data.

(b) Field data of the two performance measures was extracted from the video surveillance system of Shanxi Provincial Highway Bureau.

(c) Calibration parameters here included number of observed preceding vehicles, minimum headway, average standstill distance and waiting time before diffusion (as shown in Table 5). We chose the acceptable ranges of values by Sun et al., for this research.

(d) In the initial evaluation part, simulation data from VISSIM with default parameters were collected from 50 random seeded runs. With the limitation of the time and space of field measurement, the field data may be lower or higher than the true mean. So it is better to compare the field data with the distribution of the 50 simulation runs instead of average simulation data. The analysis results with Statistic Package for Social Science (SPSS) were shown in Figure 4.

Table 5. Default and acceptable range of candidate parameters value.

\begin{tabular}{cccc}
\hline Calibration Parameters & $\begin{array}{c}\text { Default } \\
\text { Value }\end{array}$ & $\begin{array}{c}\text { Acceptable Ranges of } \\
\text { Values by Park } \text { et al. }\end{array}$ & $\begin{array}{c}\text { Acceptable Ranges of } \\
\text { Values by Sun } \text { et al. }\end{array}$ \\
\hline number of observed preceding vehicles & 2 & $1-4$ & $1-4$ \\
minimum headway $(\mathrm{m})$ & 0.5 & $0.5-7$ & $0.5-4$ \\
average standstill distance $(\mathrm{m})$ & 2 & $1-3$ & $1-3$ \\
waiting time before diffusion $(\mathrm{s})$ & 60 & $20-40$ & $45-120$ \\
\hline
\end{tabular}


From the one-sample test of SPSS, we could find that:

(a) $p=0.128>0.05$, which means that there is no obvious difference between the average field travel time and the average simulation travel time $(p>0.05)$.

(b) $95 \%$ Confidence Interval of the Difference is $(153.7280,154.8712)$, and the average field travel time is in the $95 \%$ confidence interval.

From the one-sample test of SPSS, we could find that:

(a) $p=0.224>0.05$, which means that there is no obvious difference between the average field maximum queue length and the average simulation maximum queue length $(p>0.05)$.

(b) $95 \%$ Confidence Interval of the Difference is $(42.8802,43.2766)$, and the average field maximum queue length is in the $95 \%$ confidence interval.

Figure 4 above indicated that both average field travel time and field maximum queue length were in the given confidence interval, therefore, calibration was not necessary for this research, nor the next several steps. This also means VISSIM with default parameters could be used in the following simulation.

This study used several days of data collection and two measures of performance. It is recommended to collect more field data and to consider variability of field data if possible. In future research, we will determine whether the process is applicable to other networks or simply to this specific one.
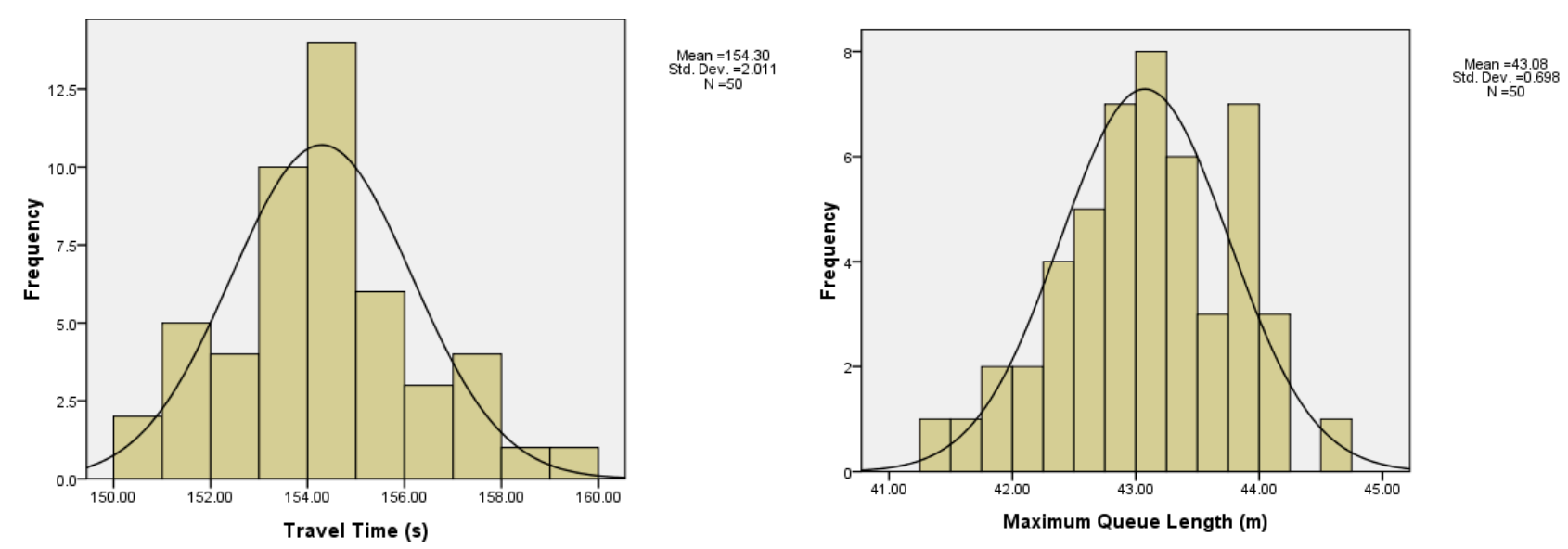

Figure 4. Eastbound left-Lane travel time distributions (left) and maximum queue length distributions (right) of default parameters.

\subsubsection{Simulation Process}

Process flow diagram of the simulation of highway segments is shown in Figure 5. The simulation in this paper was divided into three steps.

- Step 1: Determine the simulation parameters, such as the length and width of road segment, the road grades, traffic flow characteristics, vehicle velocity distribution, simulation time and the start time of data statistics, etc. (Table 6).

- Step 2: Build simulation scenarios: Add and edit road links, define the traffic distribution and the composition of traffic flow, input traffic flow and set the simulation parameters. We set 
nine research scenarios (from G1 to G9) with road grades changing from $0 \%-4 \%$ at an increment of $0.5 \%$ (Figure 6 ).

- Step 3: Run simulation and generate data: Run the simulation 10 times across all nine scenarios and output the data that were needed in calculating VSP, such as acceleration, speed, and road grades. Other related selected parameters are lane number, link number, simulation time, speed, start time, total path distance, total time in network, vehicle number, vehicle type, vehicle type name and weight (Figure 7).

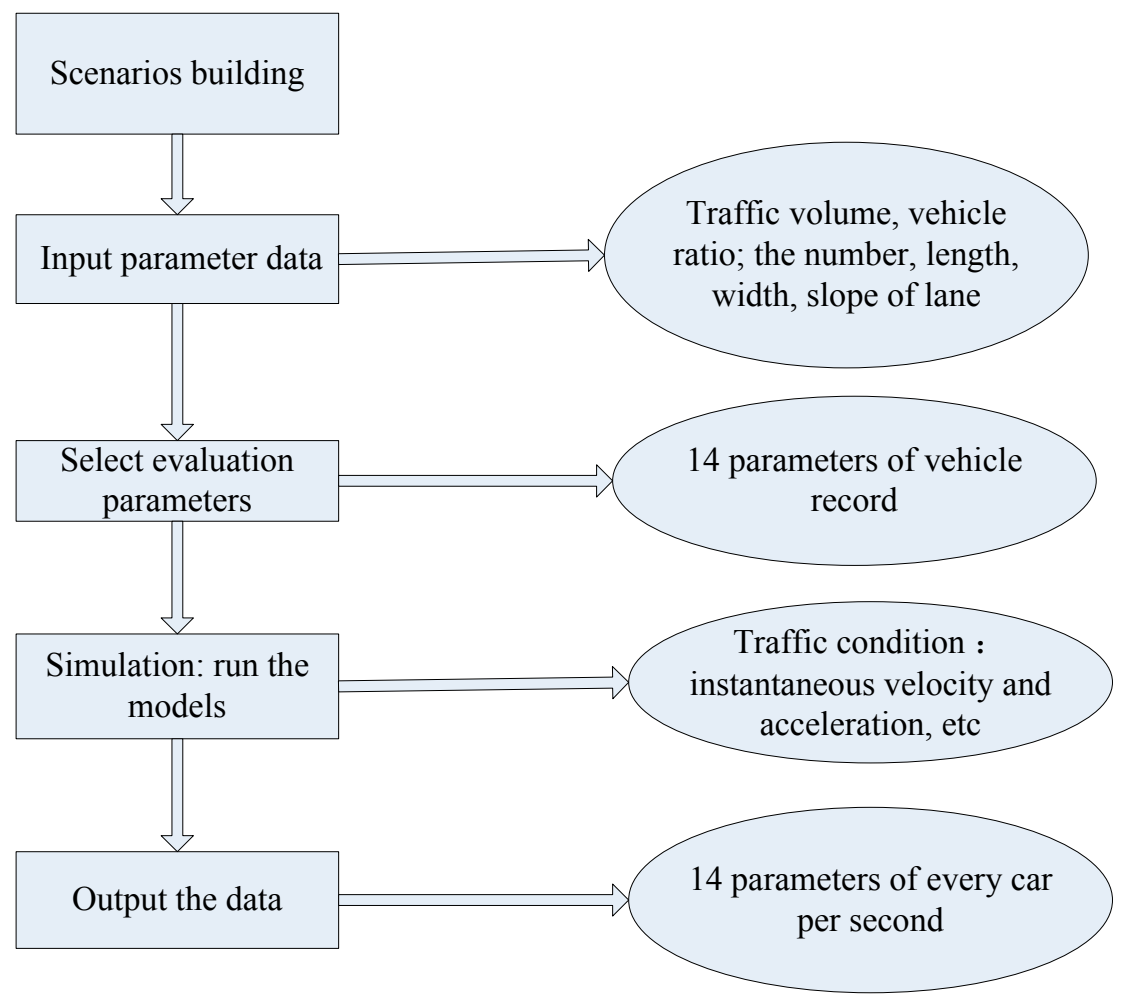

Figure 5. Process flow diagram of the simulation of highway segments.

Table 6. Simulated operation parameters based on the real condition of study area.

\begin{tabular}{cc}
\hline Characteristic Indexes & Parameters \\
\hline The length of simulation road segment $(\mathrm{m})$ & $800 *$ \\
The lane width $(\mathrm{m})$ & 3.5 \\
The traffic flow per lane $(\mathrm{veh} / \mathrm{h})$ & 300 \\
Simulation time $(\mathrm{s})$ & 300 \\
Time to start recording data $(\mathrm{s})$ & 30 \\
Distribution of vehicle velocity $(\mathrm{km} / \mathrm{h})$ & $30-60$ \\
Range of road grades $(\%)$ & $0-4$ \\
The number of lanes $($ ascent $)$ & 2 \\
The proportion of HDV $(\%)$ & 20 \\
\hline
\end{tabular}

* denotes the length of the road link was set based on China's national standard, Design Specification for Highway Alignment (JTGD20-006) and a previous paper of Pei et al., in which the ideal grades and the maximum unlimited grade lengths were stated [60]. 


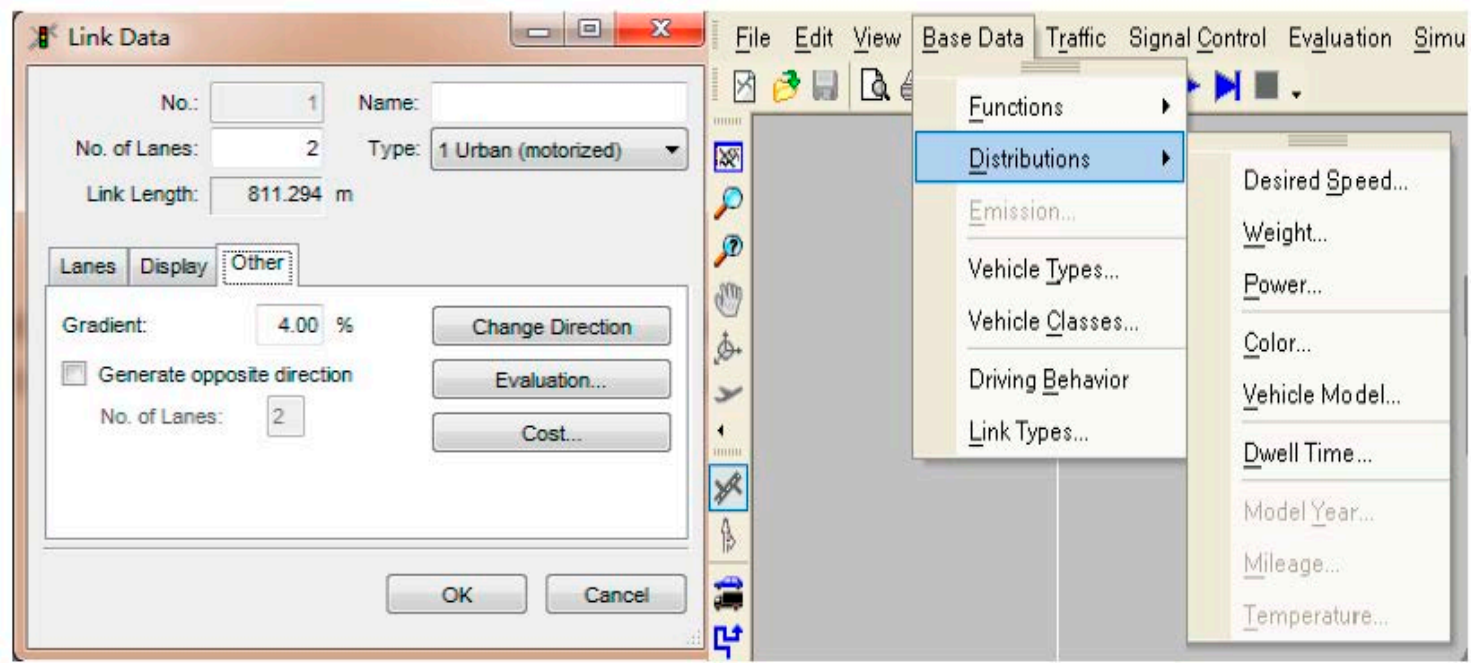

Figure 6. Set of link data and base data in scenario building.

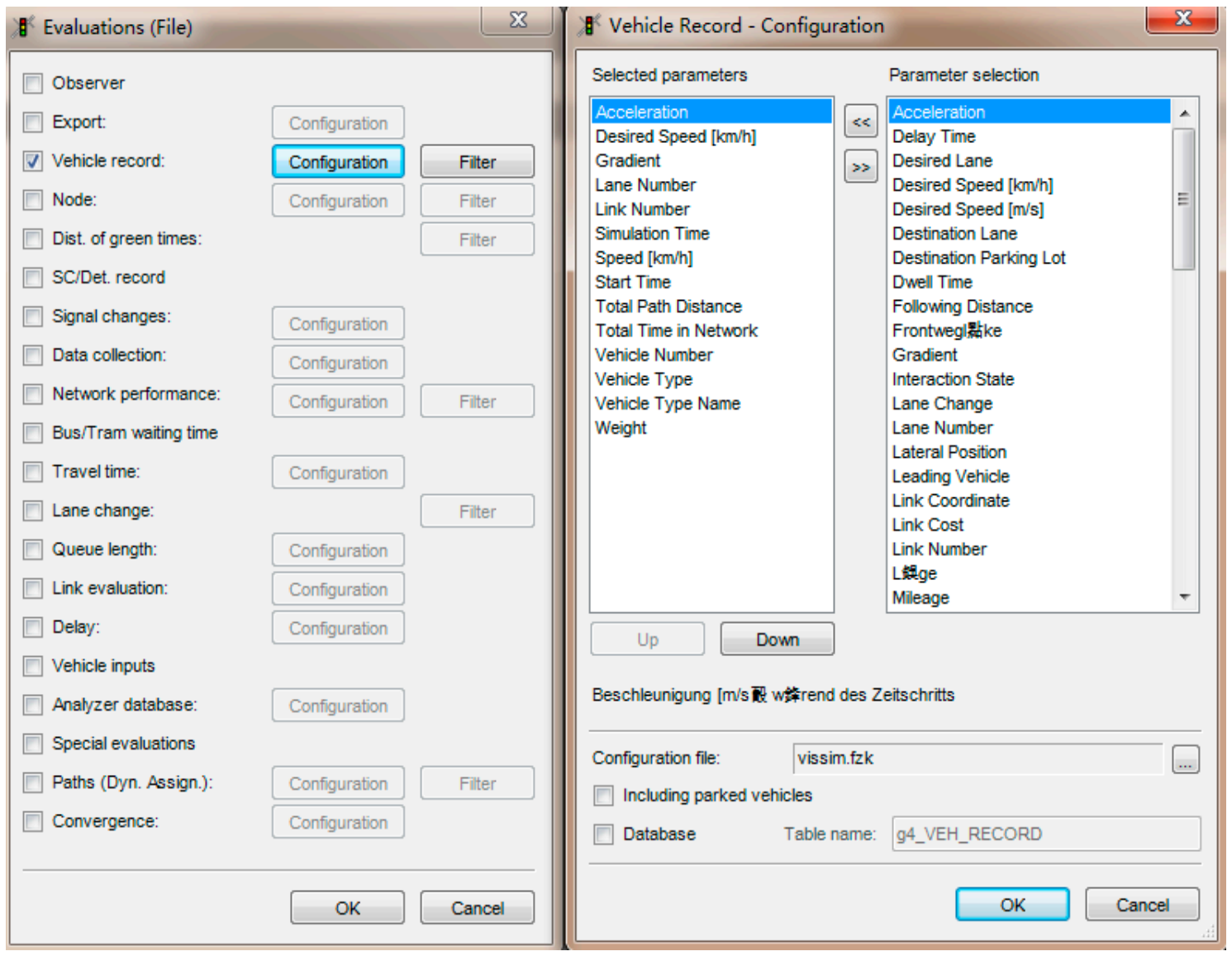

Figure 7. Set of output parameters.

\section{Results}

\subsection{The CO, HC, and $\mathrm{NO}_{x}$ Emissions across Different Scenarios}

Nearly 7800 groups of valid records were collected from VISSIM for each scenario in one simulation, adding up to over 700,000 groups of valid records for all scenarios in total. We input the results of VISSIM into formula (1) to calculate the second-by-second VSP of each HDV and the 
corresponding VSP-bin. Then, we attain the $\mathrm{CO}, \mathrm{HC}$, or $\mathrm{NO}_{\mathrm{x}}$ emissions of an $\mathrm{HDV}$ by adding up second-by-second emission in coordination with VSP-bin. Finally, we obtain the $\mathrm{CO}, \mathrm{HC}$, or $\mathrm{NO}_{\mathrm{x}}$ emissions of the road segment by adding up the emissions from all the $120 \mathrm{HDVs}(=300 \mathrm{veh} /$ lane $\times 2$ lanes $\times 20 \%)$ in the simulation. For each scenario, we averaged the results from 10 repeated simulations to increase the reliability of the results. The emission rate and total emissions of the three pollutants were listed in Tables 7 and 8.

Table 7. Emission rate of $\mathrm{CO}, \mathrm{HC}$, and $\mathrm{NO}_{\mathrm{x}}$ under different simulation scenarios.

\begin{tabular}{ccccc}
\hline No. & $\mathbf{G}(\boldsymbol{\%})$ & $\mathbf{C O}(\mathbf{m g} / \mathbf{s} \times \mathbf{v e h})$ & $\mathbf{H C}(\mathbf{m g} / \mathbf{s} \times \mathbf{v e h})$ & $\mathbf{N O}_{\mathbf{x}}(\mathbf{m g} / \mathbf{s} \times \mathbf{v e h})$ \\
\hline G1 & 0.0 & 23.037 & 3.032 & 64.774 \\
G2 & 0.5 & 25.395 & 3.503 & 74.171 \\
G3 & 1.0 & 26.763 & 3.567 & 74.882 \\
G4 & 1.5 & 28.496 & 4.087 & 76.866 \\
G5 & 2.0 & 30.694 & 3.975 & 78.117 \\
G6 & 2.5 & 32.950 & 3.969 & 78.314 \\
G7 & 3.0 & 35.085 & 4.320 & 84.083 \\
G8 & 3.5 & 36.347 & 4.278 & 87.018 \\
G9 & 4.0 & 36.493 & 4.249 & 88.520 \\
\hline
\end{tabular}

Table 8. Total emissions of $\mathrm{CO}, \mathrm{HC}$, and $\mathrm{NO}_{\mathrm{x}}$ under different simulation scenarios.

\begin{tabular}{ccccc}
\hline No. & $\mathbf{G ~ ( \% )}$ & $\mathbf{C O}(\mathbf{g})$ & $\mathbf{H C}(\mathbf{g})$ & $\mathbf{N O}_{\mathbf{x}}(\mathbf{g})$ \\
\hline G1 & 0.0 & 11.6790 & 1.5308 & 32.8692 \\
G2 & 0.5 & 12.9485 & 1.7639 & 37.9185 \\
G3 & 1.0 & 13.6412 & 1.8267 & 38.5050 \\
G4 & 1.5 & 14.4942 & 2.0907 & 39.4503 \\
G5 & 2.0 & 15.5938 & 2.0346 & 39.9430 \\
G6 & 2.5 & 16.7920 & 2.0290 & 40.0033 \\
G7 & 3.0 & 17.9477 & 2.2002 & 43.0880 \\
G8 & 3.5 & 18.6450 & 2.2095 & 44.7864 \\
G9 & 4.0 & 18.7627 & 2.2074 & 45.6840 \\
\hline
\end{tabular}

\subsection{Change Rate Analysis}

In this section, we presented the change of $\mathrm{CO}, \mathrm{HC}$ and $\mathrm{NO}_{\mathrm{x}}$ emissions when road grades change. Specifically, we employed change rate of other scenarios and baseline scenario, which indicated the variations of $\mathrm{CO}, \mathrm{HC}$ and $\mathrm{NO}_{\mathrm{x}}$ emissions between scenarios 2-9 and the baseline scenario 1 . We also used change rate of adjacent intervals to illustrate the variations of emissions between different scenarios which indicated the variations between a scenario and the adjacent scenario.

\subsubsection{CO Emissions}

The $\mathrm{CO}$ emissions grew with the increase of road grades, reflected by the increasing change rate of other scenarios and baseline scenario and positive change rates of adjacent intervals. The change rate of adjacent intervals was biggest $(0.1087)$ when the grade increased from $0 \%-0.5 \%$, followed by the 
grades increasing from $2 \%-2.5 \%(0.0768)$ and from $1.5 \%-2 \%(0.0759)$ (Figure $8 \&$ Table 9). On the contrary, when the grade increased from $3.5 \%-4 \%$, the rate of change was the smallest $(0.0063)$.

CO

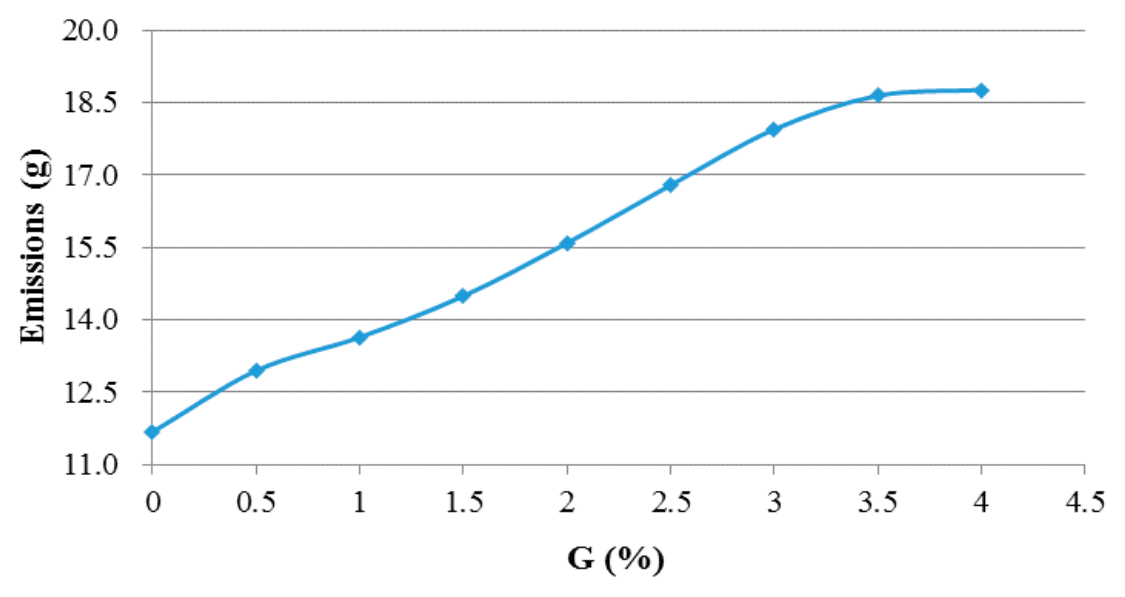

Figure 8. CO emissions of HDV in different scenarios.

Table 9. Change rate of other scenarios and baseline scenario and change rate of adjacent intervals of $\mathrm{CO}$ emissions in different scenarios.

\begin{tabular}{cccc}
\hline G (\%) & CO (g) & $\begin{array}{c}\text { Change Rate of Other Scenarios } \\
\text { and Baseline Scenario }\end{array}$ & $\begin{array}{c}\text { Change Rate of } \\
\text { Adjacent Intervals }\end{array}$ \\
\hline 0.0 & 11.6790 & - & - \\
0.5 & 12.9485 & 0.1087 & 0.1087 \\
1.0 & 13.6412 & 0.1680 & 0.0535 \\
1.5 & 14.4942 & 0.2410 & 0.0625 \\
2.0 & 15.5938 & 0.3352 & 0.0759 \\
2.5 & 16.7920 & 0.4378 & 0.0768 \\
3.0 & 17.9477 & 0.5367 & 0.0688 \\
3.5 & 18.6450 & 0.5965 & 0.0389 \\
4.0 & 18.7627 & 0.6065 & 0.0063 \\
\hline
\end{tabular}

\subsubsection{HC Emissions}

Generally, with the growth of grades, the overall $\mathrm{HC}$ emissions were increasing, as indicated by $2.2074 \mathrm{~g}$ of $\mathrm{HC}$ emissions at $4 \%$ grade and $1.5308 \mathrm{~g}$ at $0 \%$ grade. However, the variations of $\mathrm{HC}$ emissions in different scenarios were complicated, reflected by both positive and negative change rates' adjacent intervals. For example, the change rate was the biggest $(0.1523)$ when the grade increased from $0 \%-0.5 \%$, followed by the change rate of 0.1445 from $1 \%-1.5 \%$ (Figure $9 \&$ Table 10). On the contrary, when the grade changed from $1.5 \%-2 \%$, the change rate was negative $(-0.0268)$, so were the change rates from $2 \%-2.5 \%(-0.0027)$ and from $3.5 \%-4 \%(-0.0010)$. 
HC

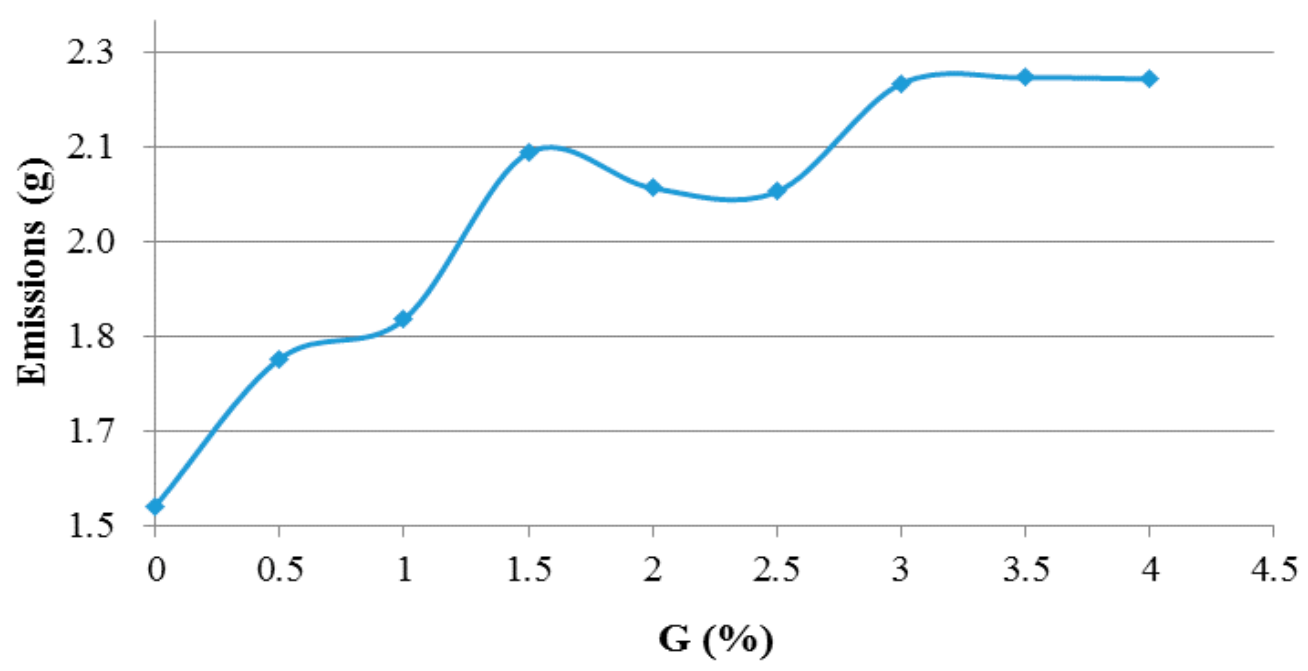

Figure 9. HC emissions of HDV in different scenarios.

Table 10. Change rate of other scenarios and baseline scenario and change rate of adjacent intervals of $\mathrm{HC}$ emissions in different scenarios.

\begin{tabular}{cccc}
\hline G (\%) & HC (g) & $\begin{array}{c}\text { Change Rate of Other Scenarios } \\
\text { and Baseline Scenario }\end{array}$ & $\begin{array}{c}\text { Change Rate of } \\
\text { Adjacent Interval }\end{array}$ \\
\hline 0.0 & 1.5308 & - & - \\
0.5 & 1.7639 & 0.1523 & 0.1523 \\
1.0 & 1.8267 & 0.1933 & 0.0356 \\
1.5 & 2.0907 & 0.3658 & 0.1445 \\
2.0 & 2.0346 & 0.3291 & -0.0268 \\
2.5 & 2.0290 & 0.3254 & -0.0027 \\
3.0 & 2.2002 & 0.4373 & 0.0844 \\
3.5 & 2.2095 & 0.4434 & 0.0043 \\
4.0 & 2.2074 & 0.4420 & -0.0010 \\
\hline
\end{tabular}

\subsection{3. $\mathrm{NO}_{\mathrm{x}}$ Emissions}

Similar to the $\mathrm{CO}$ emissions, the $\mathrm{NO}_{\mathrm{x}}$ emissions grew with the increasing of road grades. The change rate of adjacent intervals was biggest (0.1536) when the grade increased from $0 \%-0.5 \%$, followed by the change rate of grade increasing from $2.5 \%-3 \%(0.0771)$ (Figure $10 \&$ Table 11). When the grade increased from $1.5 \%-2 \%$, the change rate was the smallest $(0.0015)$. 


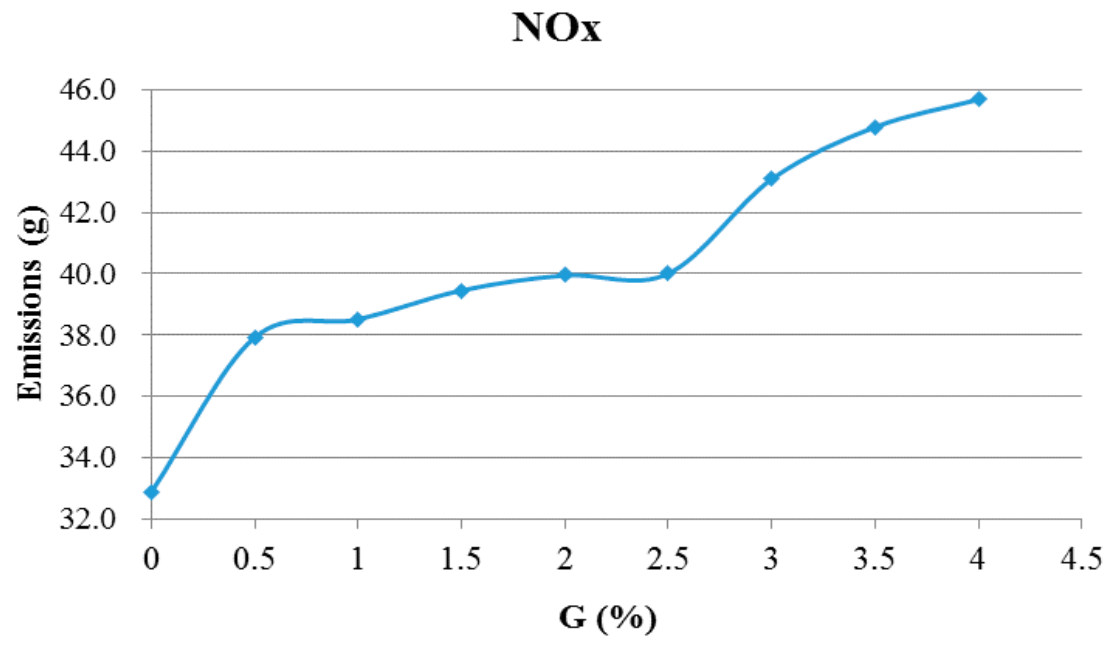

Figure 10. $\mathrm{NO}_{\mathrm{x}}$ emissions of $\mathrm{HDV}$ in different scenarios.

Table 11. Change rate of other scenarios and baseline scenario and change rate of adjacent intervals of $\mathrm{NO}_{\mathrm{x}}$ emissions in different scenarios.

\begin{tabular}{cccc}
\hline G (\%) & NO $_{\mathbf{x}}(\mathbf{g})$ & $\begin{array}{c}\text { Change Rate of Other Scenarios } \\
\text { and Baseline Scenario }\end{array}$ & $\begin{array}{c}\text { Change Rate of } \\
\text { Adjacent Intervals }\end{array}$ \\
\hline 0.0 & 32.8692 & - & - \\
0.5 & 37.9185 & 0.1536 & 0.1536 \\
1.0 & 38.5050 & 0.1715 & 0.0155 \\
1.5 & 39.4503 & 0.2002 & 0.0246 \\
2.0 & 39.9430 & 0.2152 & 0.0125 \\
2.5 & 40.0033 & 0.2170 & 0.0015 \\
3.0 & 43.0880 & 0.3109 & 0.0771 \\
3.5 & 44.7864 & 0.3626 & 0.0394 \\
4.0 & 45.6840 & 0.3899 & 0.0200 \\
\hline
\end{tabular}

\subsection{Regression Analysis}

To explore the relationship between road grades and three traffic emissions, we applied correlation analysis and polynomial regression in SPSS. The results of the correlation analysis showed that the $\mathrm{R}^{2}$ of CO, $\mathrm{HC}$, and $\mathrm{NO}_{\mathrm{x}}$ were $0.9855,0.8433$, and 0.9099 , respectively. That demonstrated fine goodness of fit of correlations of the three traffic emissions with road grades. The results of polynomial regression demonstrated better goodness of fit than correlation regression, reflected by bigger $\mathrm{R}^{2}$ (Table 12). Generally, the $\mathrm{CO}$ emissions showed the greatest goodness of fit while the $\mathrm{HC}$ emissions the least in both correlation analysis and polynomial regression.

Table 12. Polynomial regression correlation analysis between grades and three emissions.

\begin{tabular}{ccc}
\hline Three Emissions & $\boldsymbol{R}^{2}$ (for Quadratic) & $\boldsymbol{R}^{2}$ (for Cubic) \\
\hline $\mathrm{CO}$ & 0.9891 & 0.9947 \\
$\mathrm{HC}$ & 0.9326 & 0.9422 \\
$\mathrm{NO}_{\mathrm{x}}$ & 0.9116 & 0.9485 \\
\hline
\end{tabular}




\subsection{Analysis of Total Equivalent Emissions}

The $\mathrm{CO}, \mathrm{HC}$ and $\mathrm{NO}_{\mathrm{x}}$ emissions have different degrees of negative impacts on public health and environment (4). In 2012, the Ministry of Environmental Protection of China published a national standard, Method for Estimation of Environmental Impact Index of Vehicles, to regulate the evaluation of the impacts of different traffic emissions [61]. This standard involves the Weight Value (WV) that demonstrates the weighted scores of different vehicle emissions considering their impact factors on public health and environment. In specific, the WVs of $\mathrm{CO}, \mathrm{HC}$ and $\mathrm{NO}_{\mathrm{x}}$ emissions are 5 points, 10 points, and 15 points, respectively [61], showing that the negative impact of $\mathrm{NO}_{\mathrm{x}}$ is equivalent to two times of HC's and three times of CO's. Employing the Vehicle Environmental Impact Index (VEI) and WV, the calculation of the total equivalent emissions of the HDV in the study is expressed as follows:

Total Equivalent Emission $=\mathrm{CO}+2 \times \mathrm{HC}+3 \times \mathrm{NO}_{X}$

We illustrated the total equivalent emissions in different scenarios (Figure 11). The overall trend of the total equivalent emissions is similar with that of the $\mathrm{NO}_{\mathrm{x}}$ emissions. The reason is because among the three emissions, the $\mathrm{NO}_{\mathrm{x}}$ emissions have the biggest exhaust and WV. Specifically, the rate of change of adjacent intervals (0.1490) was the biggest when the grade increased from $0 \%-0.5 \%$, followed by the rate change from $2.5 \%-3 \%$ (Table 13). Meanwhile, when the grade increased from $2 \%-2.5 \%$, the rate of change rate $(0.0098)$ was the smallest.

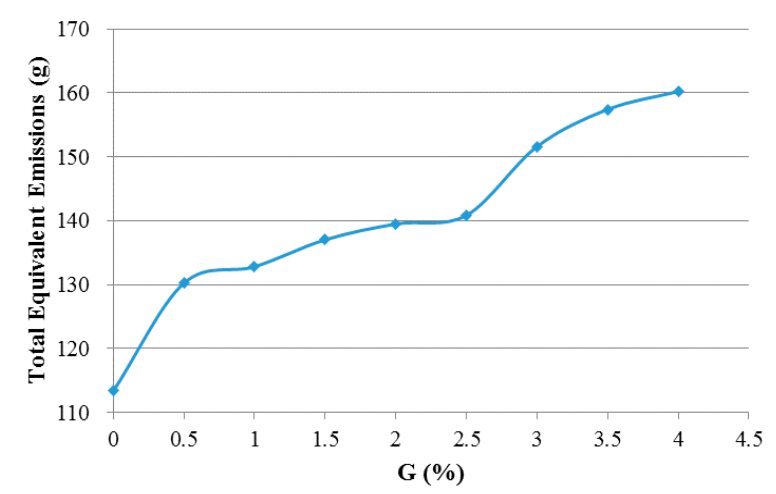

Figure 11. Total equivalent emissions of $\mathrm{CO}, \mathrm{HC}$ and $\mathrm{NO}_{\mathrm{x}}$ in different scenarios.

Table 13. Change rate of other scenarios and baseline scenario and change rate of adjacent intervals of total equivalent emissions in different scenarios.

\begin{tabular}{cccc}
\hline G (\%) & Total Equivalent Emissions (g) & $\begin{array}{c}\text { Change Rate of Other Scenarios } \\
\text { and Baseline Scenario }\end{array}$ & $\begin{array}{c}\text { Change Rate of } \\
\text { Adjacent Intervals }\end{array}$ \\
\hline 0.0 & 113.3483 & - & - \\
0.5 & 130.2317 & 0.1490 & 0.1490 \\
1.0 & 132.8095 & 0.1717 & 0.0198 \\
1.5 & 137.0266 & 0.2089 & 0.0318 \\
2.0 & 139.4919 & 0.2306 & 0.0180 \\
2.5 & 140.8598 & 0.2427 & 0.0098 \\
3.0 & 151.6122 & 0.3376 & 0.0763 \\
3.5 & 157.4233 & 0.3888 & 0.0383 \\
4.0 & 160.2294 & 0.4136 & 0.0178 \\
\hline
\end{tabular}




\section{Discussion and Policy Implications}

Considering the challenges in moving towards sustainability, this paper, taking the case of Taiyuan as an example, provided the guidance for the design of road grades that facilitates the reduction of on-road vehicle emissions and the development of sustainable transportation. This paper presented findings from a study aiming at unraveling the relationship between road grades and on-road $\mathrm{CO}, \mathrm{HC}$, and $\mathrm{NO}_{\mathrm{x}}$ emissions of heavy-duty vehicles in China. Taking a road network in Taiyuan, China, as a study area, this paper studied the relationship between road grades and $\mathrm{CO}, \mathrm{HC}$, and $\mathrm{NO}_{\mathrm{x}}$ emissions of HDVs in China for the first time. Using emissions data collected by PEMS and VSP, we first developed an emission rate model of HDVs in Taiyuan Metropolitan Area, China. This is one of the contributions of this research, which will facilitate future studies on the reduction of on-road vehicle emissions in China. We will conduct further research to refine this model by using data from more types of vehicles.

Then, we integrated the emission rate model and simulation model VISSIM to attain three traffic emissions of HDVs on nine scenarios differentiated by road grades. The results of change rate analysis and regression analysis demonstrated how road grades are associated with on-road emissions of HDVs. To reveal the different impacts of $\mathrm{CO}, \mathrm{HC}$, and $\mathrm{NO}_{\mathrm{x}}$ emissions on public health and environment, we then analyzed of the influences of road grades on total equivalent emissions based on the Chinese national standard.

For this research, the chosen vehicle provided by the Shanxi Provincial Highway Bureau represents the majority of HDVs operating in Taiyuan Metropolitan Area, China, and thus the results in this paper may not generally be valid on other roads and areas. However, using vehicles with different characteristics, such as emission control technology, fuel specifications and operating conditions, researchers can reproduce our method to obtain specific emission models for their research purpose. In addition, this paper focuses on the total emissions in the preset scenarios than the emissions in relation to the vehicles characteristics, especially the engines, so the emission results presented in the paper expressed in grams may be more appropriate than to evaluate results which are normalized in respect to the engine work, i.e., emissions in $\mathrm{g} / \mathrm{kWh}$.

The relationship of road grades on $\mathrm{CO}, \mathrm{HC}$, or $\mathrm{NO}_{\mathrm{x}}$ emissions shows some similar characteristics. Generally, road grades are highly correlated to $\mathrm{CO}, \mathrm{HC}$, or $\mathrm{NO}_{\mathrm{x}}$ emissions, as indicated by the correlation analysis and polynomial regression. Looking at the variations between two adjacent grades, for $\mathrm{CO}$ and $\mathrm{HC}$ emissions, the smallest variation of emissions appears when the grade increases from $3.5 \%-4.0 \%$. Meanwhile, the $\mathrm{NO}_{\mathrm{x}}$ emissions experience the smallest change when the grade rises from $2.0 \%-2.5 \%$. The reason for this situation remains unclear and requires further study.

With respect to the $\mathrm{CO}$ emissions, the rates of change of adjacent intervals are similar $(5.35 \%-7.68 \%)$ between the road grades of $0.5 \%$ and $3.0 \%$. When the grade is over $3.0 \%$, the rates of change of adjacent are considerably smaller $(0.63 \%-3.89 \%)$. In terms of the HC emissions, apart from the substantial increase when the grade changes from $0 \%-0.5 \%$, they also drastically increase by $14.45 \%$ and $8.44 \%$ when the grade changes from $1.0 \%-1.5 \%$ and from $2.5 \%-3.0 \%$. In other scenarios, the rates of change of adjacent are small and some are even negative. The $\mathrm{NO}_{\mathrm{x}}$ emissions will increase significantly by $15.36 \%$ and $7.71 \%$ when the grade changes from $0 \%-0.5 \%$ and $2.5 \%-3.0 \%$. Otherwise, the variations of $\mathrm{NO}_{\mathrm{x}}$ emissions are remarkably smaller $(0.15 \%-3.94 \%)$. 
The $\mathrm{CO}$ and $\mathrm{NO}_{\mathrm{x}}$ emissions increase with the road grades at all nine scenarios, demonstrating the positive effects of road grades. However, the variations of $\mathrm{HC}$ emissions in different scenarios were complicated. When the grade changed from $1.5 \%-2.5 \%$ and from $3.5 \%-4 \%$, the emissions even drop, albeit to varying degrees. This may be due to the fact that $\mathrm{HC}$ is exhausted through incomplete combustion. Previous studies indicated that a low speed leads to a low combustion temperature, which is closely related to more emissions due to incomplete combustion, especially the HC emissions [62].

One of the main purposes of this study is to illuminate strategies and interventions towards public health and environmental protection. Therefore, it is necessary to unravel the total impacts of different emissions in consideration their varying degrees of impacts on public health and the environment. To this end, we calculated the total equivalent emissions with the weight values of different emissions from the Chinese national standard Method for Estimation of Environmental Impact Index of Vehicles. As the $\mathrm{NO}_{\mathrm{x}}$ emissions have the biggest exhaust and weight value, the road grades are found to have similar influences on the total equivalent emissions as on the $\mathrm{NO}_{\mathrm{x}}$ emissions.

Currently, with the urbanization and motorization surge in China, the urban land use is developing with high density of population, employment and activities, and the on-road traffic volume is booming. For arterials connecting urban core and outskirts, the ratio of HDVs among the traffic volume is considerably high, exhausting a large amount of emissions. Hence, it is a rigorous challenge to reduce the worsening impact of on-road vehicle emissions on public health and the environment. For road networks with a high ratio of HDVs, the road grades, if applicable, are suggested to be at $0 \%$ in road design. Otherwise, the road grades should be as small as possible due to the high sensitivity of on-road emissions of HDVs to road grades.

For policy-makers and practitioners, it is important to draw up policies and strategies oriented towards reducing total equivalent emissions in road design and traffic management, so as to alleviate environmental disruption, promote public health, and develop sustainable transportation. Specifically, the total equivalent emissions are always the smallest when the road grade is $0 \%$ and biggest when the road grade is $4 \%$. Therefore, it is recommended that we design the road grade at $0 \%$ if the landform conditions allow. The total equivalent emissions witnessed the most significant increase when the grade changed from $0 \%-0.5 \%$ and from $2.5 \%-3.0 \%$. Therefore, if the landform conditions do not permit designing a level road, it is suggested that the design of road grades changing from $0 \%-0.5 \%$ or from $2.5 \%-3.0 \%$ be avoided.

\section{Strengths and Limitations}

This study had a number of strengths and limitations. In terms of the strengths, the study focused on the on-road emissions of heavy-duty vehicles, which are one of the largest sources of transport emissions in China. Secondly, the study investigated the relationship between road grades and CO, $\mathrm{HC}$, and $\mathrm{NO}_{\mathrm{x}}$ emissions of HDV in China, which has been rarely studied in existing literature. Thirdly, this study for the first time established an emission rate model for HDVs in China based on PEMS and VSP. In spite of the strengths above, this paper also had some limitations. The first one was the restriction of study area and the scope of test times and vehicles. In terms of the road grades alone, a study on the distribution of the real road grades, which includes uphill road, downhill road and the combined uphill-and-downhill roads, may be needed for building the next simulation scenarios. For this reason, the 
results might not necessarily apply to other road networks in China with characteristics that were different from the study area. Secondly, this study focused on three major kinds of traffic emissions. Future studies may expand to other emissions including $\mathrm{CO}_{2}$ and particle pollution (PM).

\section{Conclusions}

On-road vehicle emissions are one of the major sources of transport emissions. As a key geometric design factor, road grade significantly affects on-road vehicle emissions, particularly for heavy-duty vehicles (HDVs). In this paper, we presented research results from a study aiming at unraveling the influences of road grades on $\mathrm{CO}, \mathrm{HC}$ and $\mathrm{NO}_{\mathrm{x}}$ emissions of $\mathrm{HDVs}$, with data collected from Taiyuan Metropolitan Area, China. Firstly, in the section on on-road emission testing, we developed an emission rate model of HDVs under VSP-bins with the data collected from a PEMS, OBEAS-3000, in Taiyuan. The establishment of this model contributes to facilitating future studies on the reduction of on-road vehicle emissions in China. Secondly, in the section on simulation, with the integration of an emission rate model of HDVs and VISSIM, we calculated the $\mathrm{CO}, \mathrm{HC}$, and $\mathrm{NO}_{\mathrm{x}}$ emissions of HDVs in nine simulation scenarios differentiated according to road grades (from $0 \%-4 \%$ ). Then, we statistically analyzed how road grades are associated with the $\mathrm{CO}, \mathrm{HC}$, and $\mathrm{NO}_{\mathrm{x}}$ emissions and the total equivalent emissions of HDVs. Finally, based on the research findings, we discussed strategies oriented towards reducing emissions of HDVs.

The relationship of road grades with the $\mathrm{CO}, \mathrm{HC}$, or $\mathrm{NO}_{\mathrm{x}}$ of $\mathrm{HDV}$ shows some similar characteristics. The three emissions are found to be highly correlated to road grades, among which the $\mathrm{CO}$ emissions are most sensitive to the change of road grades and the $\mathrm{HC}$ emissions least. All three emissions experience the biggest change, ranging from $10.9 \%(\mathrm{CO})$ to $15.4 \%$ (HC), when the road grade rises from $0 \%-0.5 \%$. HDVs exhaust least $\mathrm{CO}, \mathrm{HC}$, or $\mathrm{NO}_{\mathrm{x}}$ emissions when the road grade is $0 \%$ and most at $4 \%$. Compared to the emissions at $0 \%$, the emissions at $4 \%$ grade will be substantially boosted from $39.0 \%-60.6 \%$, among which the $\mathrm{CO}$ emissions see the biggest rise and $\mathrm{HC}$ the smallest. The $\mathrm{CO}$ and $\mathrm{NO}_{\mathrm{x}}$ emissions increase with the road grades in all nine scenarios, demonstrating the positive effects of road grades. However, the variations of $\mathrm{HC}$ emissions in different scenarios were complicated. This may be due to the fact that $\mathrm{HC}$ is exhausted through incomplete combustion. Looking at the total equivalent emissions, road grades are found to have similar influences on them as on the $\mathrm{NO}_{\mathrm{x}}$ emissions.

The findings of this study will facilitate our understanding on the relationship between road grades and on-road vehicle emissions of HDVs. The findings will also provide insights for policy-makers, scholars and practitioners in China into the improvement of road grade design with an attempt to reduce traffic emissions, alleviate environmental disruption, promote public health, and develop sustainable transportation, with the ultimate aim of moving towards sustainability in the future.

\section{Acknowledgments}

The authors acknowledge the financial support of Project 2012-1-15 by Transport Department of Shanxi Province, Project 12N11 by Transport Department of Jiangsu Province, Project 12\&ZD203 and 14BSH032 by National Social Science Foundation of China, and Project 51308336 and 51408065 by National Natural Science Foundation of China. 


\section{Author Contributions}

In this paper, Wendan Zhang designed the research programs, participated in the data collection, analyzed the results, and completed the writing of the introduction, results and discussion; Jian Lu committed to the design of the survey and data collection, and the writing of corresponding parts; Ping $\mathrm{Xu}$ carried out the data process and completed the writing work of corresponding parts; and Yi Zhang conceived and developed the research ideas and led the research in general.

\section{Conflicts of Interest}

The authors declare no conflict of interest.

\section{Abbreviation List}

$\begin{array}{ll}\text { HDVs } & \text { Heavy-Duty Vehicles } \\ \text { HC } & \text { Carbon Monoxide } \\ \text { NOx } & \text { Hydrocarbons } \\ \text { CO2 } & \text { Nitrogen Oxides } \\ \text { PEMS } & \text { Carbon Dioxide } \\ \text { VSP } & \text { Portable Emission Measurement System } \\ \text { U.S. } & \text { Vehicle Specific Power } \\ \text { EU } & \text { United States } \\ \text { MOBILE } & \text { European Union } \\ \text { MOVES } & \text { Mobile Source Emissions Factor Model } \\ \text { EPA } & \text { Motor Vehicle Emission Simulator } \\ \text { CMEM } & \text { Environmental Protection Agency } \\ \text { NCHRP } & \text { Comprehensive Modal Emissions Model } \\ \text { IVE } & \text { National Cooperative Highway Research Program } \\ \text { VISSIM } & \text { International Vehicle Emissions } \\ \text { ETC } & \text { Verkehr In Städten-SIMulationsmodell } \\ \text { HOV } & \text { Electronic Toll Collection } \\ \text { GDP } & \text { High Occupancy Vehicle } \\ \text { GPS } & \text { Gross Domestic Product } \\ \text { OBD } & \text { Global Positioning System } \\ \text { FAW } & \text { On-Board Diagnostics } \\ \text { EGR } & \text { First Automotive Works } \\ \text { FEUP } & \text { Exhaust Gas Recirculation } \\ \text { SPSS } & \text { FAW Electronic Unit Pump } \\ \text { WV } & \text { Statistic Package for Social Science } \\ \text { VEI } & \text { Weight Value } \\ & \text { Vehicle Environmental Impact Index } \\ & \end{array}$




\section{References}

1. World Health Organization. Ambient (Outdoor) Air Quality and Health; Fact sheet N. 313; World Health Organization: Geneva, Switzerland, 2014.

2. Maykut, N.N.; Lewtas, J.; Kim, E.; Larson, T.V. Source apportionment of PM 2.5 at an urban IMPROVE site in Seattle, Washington. Environ. Sci. Technol. 2003, 37, 5135-5142.

3. Querol, X.; Viana, M.; Alastuey, A.; Amato, F.; Moreno, T.; Castillo, S.; Pey, J.; de la Rosa, J.; de La Campa, A.S.; Artíñano, B. Source origin of trace elements in PM from regional background, urban and industrial sites of Spain. Atmos. Environ. 2007, 41, 7219-7231.

4. Franco, V.; Kousoulidou, M.; Muntean, M.; Ntziachristos, L.; Hausberger, S.; Dilara, P. Road vehicle emission factors development: A review. Atmos. Environ. 2013, 70, 84-97.

5. U.S. Environmental Protection Agency. Development of Emission Rates for Light-Duty Vehicles in the Motor Vehicle Emissions Simulator (MOVES2010); U.S. Environmental Protection Agency: Washington, DC, USA, 2011.

6. Guerreiro, C.; de Leeuw, F.; Foltescu, V.; Horálek, J. Air Quality in Europe-2014 Report; European Environment Agency: Copenhagen, Denmark, 2014.

7. EC European Commission. WHITE PAPER roadmap to a single European transport area towards a competitive and resource efficient transport system. Available online: http://ec.europa.eu/ transport/themes/strategies/doc/2011_white_paper/white_paper_com\%282011\%29_144_en.pdf (accessed on 5 January 2015).

8. Fang, K.; Heijungs, R.; Duan, Z.; de Snoo, G.R. The Environmental Sustainability of Nations: Benchmarking the Carbon, Water and Land Footprints against Allocated Planetary Boundaries. Sustainability 2015, 7, 11285-11305.

9. Disley, Y.P. Sustainable development goals for people and planet. Nature 2013, 495, 305-307.

10. Yang, J.; Yuan, M.; Yigitcanlar, T.; Newman, P.; Schultmann, F. Managing Knowledge to Promote Sustainability in Australian Transport Infrastructure Projects. Sustainability 2015, 7 , 8132-8150.

11. Qin, F.; Zhang, X. Designing an Optimal Subsidy Scheme to Reduce Emissions for a Competitive Urban Transport Market. Sustainability 2015, 7, 11933-11948.

12. Zhang, C.; Jiang, Y.; Zhang, Y.; Bing, X.; Lu, J. An optimal speed limit investigation on highway for emission reductions. Adv. Transp. Stud. 2014, 33, 33-46.

13. Silva, C.; Farias, T.; Frey, H.C.; Rouphail, N.M. Evaluation of numerical models for simulation of real-world hot-stabilized fuel consumption and emissions of gasoline light-duty vehicles. Transp. Res. Part D Transp. Environ. 2006, 11, 377-385.

14. Bing, X.; Jiang, Y.; Zhang, C.; Zhang, Y.; Lu, J. Effects of intersection lane configuration on traffic emissions. Adv. Transp. Stud. 2014, 32, 23-36.

15. Boriboonsomsin, K.; Barth, M. Impacts of road grade on fuel consumption and carbon dioxide emissions evidenced by use of advanced navigation systems. Transp. Res. Rec. J. Transp. Res. Board 2009, 2139, 21-30.

16. Chamberlin, R.; Swanson, B.; Talbot, E.; Dumont, J.; Pesci, S. Analysis of MOVES and CMEM for evaluating the emissions impact of an intersection control change. In Proceedings of the Transportation Research Board 90th Annual Meeting, Washington, DC, USA, 23-27 January 2011. 
17. Cicero-Fernández, P.; Long, J.R.; Winer, A.M. Effects of grades and other loads on on-road emissions of hydrocarbons and carbon monoxide. J. Air Waste Manag. Assoc. 1997, 47, 898-904.

18. Hao, Y.; Yu, L.; Song, G.; Xu, Y.; Wang, H. Analysis of Driving Behavior and Emission Characteristics for Diesel Transit Buses Using PEMS'Measurements. In Proceedings of the Transportation Research Board 89th Annual Meeting, Washington, DC, USA, 10-14 January 2010.

19. Noland, R.B.; Quddus, M.A. Flow improvements and vehicle emissions: effects of trip generation and emission control technology. Transp. Res. Part D 2006, 11, 1-14.

20. Stevanovic, A.; Stevanovic, J.; Zhang, K.; Batterman, S. Optimizing traffic control to reduce fuel consumption and vehicular emissions: Integrated approach with VISSIM, CMEM, and VISGAOST. Transp. Res. Rec. J. Transp. Res. Board 2009, 2128, 105-113.

21. Frey, H.C.; Zhang, K.; Rouphail, N.M. Fuel use and emissions comparisons for alternative routes, time of day, road grade, and vehicles based on in-use measurements. Environ. Sci. Technol. 2008, 42, 2483-2489.

22. Boroujeni, B.Y.; Frey, H.C. Road grade quantification based on global positioning system data obtained from real-world vehicle fuel use and emissions measurements. Atmos. Environ. 2014, 85, 179-186.

23. Wyatt, D.W.; Li, H.; Tate, J.E. The impact of road grade on carbon dioxide $\left(\mathrm{CO}_{2}\right)$ emission of a passenger vehicle in real-world driving. Transp. Res. Part D 2014, 32, 160-170.

24. Prati, M.V.; Costagliola, M.A.; Tommasino, C.; Della Ragione, L.; Meccariello, G. Road Grade Influence on the Exhaust Emissions of a Scooter Fuelled with Bioethanol/Gasoline Blends. Transp. Res. Procedia 2014, 3, 790-799.

25. Alam, A.; Hatzopoulou, M. Investigating the isolated and combined effects of congestion, roadway grade, passenger load, and alternative fuels on transit bus emissions. Transp. Res. Part D Transp. Environ. 2014, 29, 12-21.

26. Kern, J.; Clark, N.; Nine, R. Factoring terrain effects into vehicle emissions modeling and inventory. In Proceedings of the 10th Annual Coordinating Research Council On-Road Vehicle Emissions Workshop, San Diego, CA, USA, 27-29 March 2000.

27. Zhang, K.; Frey, H.C. Road grade estimation for on-road vehicle emissions modeling using light detection and ranging data. J. Air Waste Manag. Assoc. 2006, 56, 777-788.

28. Frey, H.C.; Unal, A.; Rouphail, N.; Colyar, J. Use of on-board tailpipe emissions measurements for development of mobile source emission factors. In Proceedings of the US Environmental Protection Agency Emission Inventory Conference, Atlanta, GA, USA, 15-18 April 2002; pp. 1-13.

29. Yerramalla, A. Vehicular Emissions Models Using MOBILE6. 2 and Field Data; The University of Texas at Arlington: Austin, TX, USA, 2007.

30. Koupal, J.; Michaels, H.; Cumberworth, M.; Bailey, C.; Brzezinski, D. EPA's plan for MOVES: A comprehensive mobile source emissions model. In Proceedings of the 12th CRC On-Road Vehicle Emissions Workshop, San Diego, CA, USA, 15-17 April 2002; Coordinating Research Council: Alpharetta, GA, USA, 2002; pp. 15-17.

31. Rakha, H.; Ahn, K.; Trani, A. Comparison of MOBILE5a, MOBILE6, VT-MICRO, and CMEM models for estimating hot-stabilized light-duty gasoline vehicle emissions. Can. J. Civ. Eng. 2003, 30, 1010-1021. 
32. Nicole, D.; Lents, J.; Osses, M.; Nikkila, N.; Barth, M. Development and application of an international vehicle emissions model. Transp. Res. Rec. J. Transp. Res. Board 2005, 1939, $155-165$.

33. Jimenez-Palacios, J.L. Understanding and Quantifying Motor Vehicle Emissions with Vehicle Specific Power and TILDAS Remote Sensing. Ph.D. Thesis, Massachusetts Institute of Technology, Cambridge, MA, USA, 1998.

34. Koupal, J.; Cumberworth, M.; Michaels, H.; Beardsley, M.; Brzezinski, D. Draft Design and Implementation Plan for EPA's Multi-Scale Motor Vehicle and Equipment Emission System (MOVES); US Environmental Protection Agency: Washington, DC, USA, 2002.

35. Qi, Y.G.; Teng, H.H.; Yu, L. Microscale emission models incorporating acceleration and deceleration. J. Transp. Eng. 2004, 130, 348-359.

36. Song, G.; Yu, L.; Zhang, Y. Applicability of traffic microsimulation models in vehicle emissions estimates: Case study of VISSIM. Transp. Res. Rec. J. Transp. Res. Board 2012, 2270, 132-141.

37. Lv, J.; Zhang, Y. Effect of signal coordination on traffic emission. Transp. Res. Part D 2012, 17, 149-153.

38. Bartin, B.; Mudigonda, S.; Ozbay, K. Impact of electronic toll collection on air pollution levels: Estimation using microscopic simulation model of large-scale transportation network. Transp. Res. Rec. J. Transp. Res. Board 2007, 2011, doi:10.3141/2011-08.

39. McCormick, R.L. The impact of biodiesel on pollutant emissions and public health. Inhal. Toxicol. 2007, 19, 1033-1039.

40. Aashto, A. Policy on Geometric Design of hIGHWAYS and Streets; American Association of State Highway and Transportation Officials: Washington, DC, USA, 2001.

41. Ko, M.; Lord, D.; Zietsman, J. Environmentally Conscious Highway Design for Vertical Grades. Transp. Res. Rec. J. Transp. Res. Board 2013, 2341, 53-65.

42. Ministry of Environmental Protection of the People's Republic of China; General Administration of Quality Supervision Inspection and Quarantine of the People's Republic of China. Limits and Measurement Method for Exhaust Pollutants from Compression Ignition and Gas Fuelled Positive Ignition Engines of Vehicles (III, IV, V); China Environmental Publishing: Beijing, China, 2005.

43. Zhang, Y.; Yang, X.; Liu, Q.; Li, C. Who Will Use Pre-Trip Traveler Information and How Will They Respond? Insights from Zhongshan Metropolitan Area, China. Sustainability 2015, 7, 5857-5874.

44. Zhang, Y.; Yang, X.; Li, Y.; Liu, Q.; Li, C. Household, Personal and Environmental Correlates of Rural Elderly's Cycling Activity: Evidence from Zhongshan Metropolitan Area, China. Sustainability 2014, 6, 3599-3614.

45. Wu, W.; Li, P.K.; Zhang, Y. Modelling and Simulation of Vehicle Speed Guidance in Connected Vehicle Environment. Int. J. Simul. Model. 2015, 14, 145-157.

46. Zhang, Y.; Li, Y.; Liu, Q.; Li, C. The Built Environment and Walking Activity of the Elderly: An Empirical Analysis in the Zhongshan Metropolitan Area, China. Sustainability 2014, 6, 1076-1092.

47. Zhang, Y.; Li, Y.; Yang, X.; Liu, Q.; Li, C. Built Environment and Household Electric Bike Ownership. Transp. Res. Rec. J. Transp. Res. Board 2013, 2387, 102-111. 
48. Zhang, Y.; Wu, W.; Li, Y.; Liu, Q.; Li, C. Does the Built Environment Make a Difference? An Investigation of Household Vehicle Use in Zhongshan Metropolitan Area, China. Sustainability 2014, 6, 4910-4930.

49. Fulton, L.; Cazzola, P.; Cuenot, F.; Kojima, K.; Onoda, T.; Staub, J.; Taylor, M. Transport, Energy and CO2: Moving toward Sustainability; International Energy Agency: Paris, France, 2009.

50. McKibbin, W.J.; Morris, A.C.; Wilcoxen, P.J. Comparing climate commitments: A model-based analysis of the Copenhagen Accord. Clim. Chang. Econ. 2011, 2, 79-103.

51. National Bureau of Statistics of the People's Republic of China. China Statistical Yearbook 2014; China Statistics Press: Beijing, China, 2014.

52. Wang, H.; Yu, L.; Hao, H.; Song, G.; Guo, Y. Calculation of Vehicle Specification Power for Heavy-duty Vehicles. Saf. Environ. Eng. 2011, 18, 124-128.

53. Xu, Y.; Yu, L.; Song, G. VSP-Bin division for light-duty vehicles oriented to carbon dioxide. Acta Sci. Circumst. 2010, 30, 1358-1365.

54. Fellendorf, M.; Vortisch, P. Validation of the microscopic traffic flow model VISSIM in different real-world situations. In Proceedings of the Transportation Research Board 80th Annual Meeting, Washington, DC, USA, 7-11 January 2001.

55. Yadlapati, S.; Park, B. Development and Testing of Variable Speed Limit Logics at Work Zones Using Simulation. Master's Thesis, University of Virginia, Charlottesville, VA, USA, 2004.

56. Park, B.; Schneeberger, J. Microscopic Simulation Model Calibration and validation: case study of VISSIM simulation model for a coordinated actuated Signal system. Transp. Res. Rec. J. Transp. Res. Board 2003, 1856, 185-192.

57. Milam, R.T.; Choa, F. Recommended guidelines for the calibration and validation of traffic simulation models. In Proceedings of the Eighth TRB Conference on the Application of Transportation Planning Methods, Corpus Christi, TX, USA, 22-26 April 2002.

58. Jian, S.; Xiao-guang, Y. Research into microscopic traffic simulation model systematic parameter calibration: A case study of VISSIM. Comput. Commun. 2004, 22, 3-6.

59. Sun, J.; Yang, X.-G.; Liu, H.-D. Study on Microscopic traffic simulation model systematic parameter calibration. J. Syst. Simul. 2007, 1, 48-50.

60. Pei, Y.-L.; Xing, E.-H. Grade and its length limitation analysis of highway. J. Harbin Inst. Technol. 2005, 37, 629-632.

61. Ministry of Environmental Protection of the People's Republic of China. Method for Estimation of Environmental Impact Index of the Light-Duty Vehicle; Ministry of Environmental Protection of the People's Republic of China: Beijing, China, 2010.

62. Gao, M.; Huang, W.; Wan, X. Study on the emission characteristics of LNG buses based on PEMS. Environ. Eng. 2014, 11, 151-154.

(C) 2015 by the authors; licensee MDPI, Basel, Switzerland. This article is an open access article distributed under the terms and conditions of the Creative Commons Attribution license (http://creativecommons.org/licenses/by/4.0/). 